\title{
Hibiscus sabdariffa extract protects HT-22 cells from glutamate-induced neurodegeneration by upregulating glutamate transporters and exerts lifespan extension in C. elegans via DAF-16 mediated pathway
}

\author{
Dicson Sheeja Malar ${ }^{\mathrm{a}, \mathrm{b}}$, Mani Iyer Prasanth ${ }^{\mathrm{a}, \mathrm{b}}$, James Michael Brimson ${ }^{\mathrm{a}, \mathrm{b}}$, Kanika Verma ${ }^{\mathrm{c}}$, \\ Anchalee Prasansuklab ${ }^{\mathrm{a}, \mathrm{d}}$ and Tewin Tencomnao ${ }^{\mathrm{a}, \mathrm{b}, *}$ \\ ${ }^{a}$ Natural Products for Neuroprotection and Anti-ageing Research Unit, Chulalongkorn University, Bangkok, \\ Thailand \\ ${ }^{\mathrm{b}}$ Department of Clinical Chemistry, Faculty of Allied Health Sciences, Chulalongkorn University, Bangkok, \\ Thailand \\ ${ }^{\mathrm{c}}$ ICMR-The National Institute of Research in Tribal Health, Garha Jabalpur, Madhya Pradesh, India \\ ${ }^{\mathrm{d}}$ College of Public Health Sciences, Chulalongkorn University, Bangkok, Thailand
}

Received 5 June 2021

Accepted 20 August 2021

Pre-press 10 September 2021

Published 2 November 2021

\begin{abstract}
.
BACKGROUND: Glutamate toxicity is involved in several neurodegenerative conditions, including Alzheimer's disease. OBJECTIVE: The study aims to investigate the neuroprotective efficacy of ethanol extract of Hibiscus sabdariffa calyces (HS) against glutamate-induced toxicity in HT-22 cells and anti-aging property in Caenorhabditis elegans.

METHODS: HT-22 cells were pre-treated with HS followed by glutamate and evaluated for the neuroprotective effect using cell viability assay, confocal microscopic analysis, qPCR, Western blot, and docking analysis. Induction of anti-aging property in C. elegans with HS extract was analyzed through physiological assays and qPCR analysis.

RESULTS: GC-MS analysis of the HS extract showed the presence of 19 compounds with antioxidant properties including oleamide, 2-(diethoxymethyl)furan and 5-methylfurfural. In vitro studies reveal that glutamate exerted toxicity in HT-22 cells by inducing oxidative stress, depleting glutathione, downregulating glutamate transporters, antioxidant genes, inducing autophagy (Beclin-1, Atg-5, Atg-7, LC3-II) by the activation of MAPK (p38, JNK) pathway, and causing apoptosis. However, pre-treatment with HS extract $(5,10 \mu \mathrm{g} / \mathrm{ml})$ reversed the effect and offered neuroprotection. In silico studies showed that the compounds of HS extract can bind effectively and inhibit the activity of NMDAR, calpain-1 and GSK-3 $\beta$. In C. elegans, HS extended lifespan, reduced the accumulation of lipofuscin, modulated healthspan-related genes and downregulated the expression of $d a f-2$.

CONCLUSION: Our results indicate that HS with its bioactive components exhibits neuroprotective activity by upregulating glutamate transporters, inhibiting autophagy and exerts anti-aging property through DAF-16 dependent mechanism.
\end{abstract}

Keywords: Oxidative stress, glutamate transporters, mitochondrial membrane potential, autophagy, C. elegans

\section{Introduction}

${ }^{*}$ Corresponding author: Tewin Tencomnao, Tel.: +66 2218

1533; E-mail: tewin.t@ chula.ac.th.

Glutamate is an excitatory neurotransmitter involved mainly in maintaining synaptic plastic- 
ity, memory, and learning [1]. It is synthesized through several metabolic pathways and its availability at appropriate levels for cellular signaling is strictly under the control of glutamate uptake and recycling mechanisms. Neurotoxicity mediated by glutamate occurs through two mechanisms; glutamate receptor-dependent and independent pathways [2]. The excitatory neurotransmission occurs chiefly through ligand-gated ionotropic glutamate receptors (iGluRs) mainly via N-methyl-D-aspartate receptor (NMDAR) [3]. Blockade of NMDAR functions results in neuronal apoptosis and degeneration while activation by glutamate triggers $\mathrm{Ca}^{2+}$ dependent transcription factors and leads to the expression of several genes involved in cell survival under normal conditions [4]. However, stimulation of excessive signaling results in glutamate excitotoxicity, in which neuronal cells are damaged and degenerated. Exogenous supply of glutamate to neuronal cells contributes to neurotoxicity mainly by inducing the levels of reactive oxygen species (ROS), indicating oxidative stress to be the underlying factor in neurodegeneration. Oxidative stress can trigger a cascade of events, including depletion of glutathione, mitochondrial dysfunction, endoplasmic reticulum (ER) stress, autophagy, and apoptosis [2]. Therefore, maintaining the synapse's physiological level of glutamate is essential for preventing toxicity and sustaining normal signal transmission. Removal of excess glutamate is mainly accomplished by transporter-mediated uptake by glutamate transporters [5]. Studies indicate that glutamate uptake is highly reduced during Alzheimer's disease conditions owing to the failure of the glutamate uptake and recycling process, due to which excitotoxic condition prevails, further contributing to the disease [6]. In the current study the mouse hippocampal neuronal cell line HT22 has been used as an in vitro model to explore glutamate-mediated oxidative stress conditions as it lacks NMDAR receptor, thus showing resistance to excitotoxicity. Pioneering studies have predicted that glutamate competes with cystine transport inhibiting the process in the cell resulting in the depletion of glutathione and causing oxidative stress [7, 8].

Humans rely on plant-based medicinal system for the treatment of various diseases because of their high efficacy and low toxic profile. Most of the pharmaceuticals, which are currently in use by the healthcare has been derived from plants [9]. Plants have often been used to improve cognitive functions and retain the mental ability for centuries. Recent studies from our lab have reported the neuroprotective efficacies of various plant extracts, including Kaempferia parviflora, Cleistocalyx nervosum, Bacopa monnieri, and Citrus hystrix against toxic insults in cellular and nematode models [10-14].

The simple nematode model system Caenorhabditis elegans has been widely used in the recent past for the investigation of important biological aspects including neurodegeneration, aging, calorie restriction and reproduction [15]. In addition to exploring the molecular processes, it has developed as a powerful model for the study of drug actions against various pathological events due to their short life cycle, ease of handling and maintenance when compared to higher model organisms. Further, several transgenic/mutant strains that mimic human diseases are available, which makes it easier to understand and identify the molecular mechanisms, targets and modifiers underlying the pathological conditions $[16$, 17].

Hibiscus sabdariffa, commonly known as roselle belongs to the family Malvaceae and is commonly grown in tropical and sub-tropical regions [18]. It is commonly used as a food, drink, flavoring agent and traditional medicinal herb to treat hyperlipidemia, hypertension, inflammation, and liver disorders [19, 20]. Anthocyanin-rich extract from the calyces has been reported to reverse streptozotocin-induced Alzheimer's disease in mice by downregulating the expression of BACE-1 and A $\beta 42$ as well as ameliorating oxidative stress [21]. Ethyl acetate fraction of the plant leaves exhibited ameliorating effect against diabetes-associated cognitive impairment in mice by improving the cholinergic system and reducing the expression of p-Tau [22]. Ethanol extract of the calyces exhibits a protective effect against serum/glucose-induced apoptosis in PC12 cells [23]. The current study aims to evaluate the neuroprotective and anti-aging efficacy of ethanol extract of $H$. sabdariffa calyces (HS) in HT-22 cells and the in vivo model system Caenorhabditis elegans.

\section{Materials and methods}

\subsection{Chemicals}

Dulbecco's modified Eagle medium (DMEM), fetal bovine serum (FBS) and penicillin-streptomycin solution were procured from HyClone, USA. Monoclonal rabbit primary antibodies (JNK, p-JNK, p38, p-p38, LC-3B, $\beta$-actin) were purchased from Cell Signaling Technology, USA). EAAT-3 was purchased 
from Santa Cruz Biotechnology, USA. Anti-rabbit IgG- HRP linked secondary antibody, Rhodamine 123 (Rh 123), 2',7'-Dichlorofluorescin Diacetate (DCFH-DA) were purchased from Sigma Aldrich, USA. The Amersham ECL select Western blotting detection reagent was purchased from GE Healthcare, USA. All other chemicals and solvents used in the experiments are of high grade and purity.

\subsection{Plant collection and extraction}

Fresh roselle flowers (Hibiscus sabdariffa) were brought from a local market in Khlong Luang District, Pathum Thani province, Thailand. The plant was authenticated (Accession number: BCU-17029) by the herbarium of Kasin Suvatabhandhu (Department of Botany, Faculty of Science, Chulalongkorn University, Thailand). The red calyces were separated from the seeds, cleaned, and dried before being ground into a fine powder. For extraction, about $40 \mathrm{~g}$ of powdered plant material was uniformly packed into a thimble and extracted in a Soxhlet apparatus with $400 \mathrm{ml}$ of ethanol for $24 \mathrm{~h}$. The resulting supernatant was collected, filtrated, and evaporated to dryness under vacuum. Finally, stock solution of the extract was prepared in sterile MilliQ water at $100 \mathrm{mg} / \mathrm{ml}$, subsequently sterilized with a $0.2 \mu \mathrm{m}$ pore size syringe filter, and stored at $-20^{\circ} \mathrm{C}$ until further use.

\subsection{DPPH assay}

To the ethanol extract of HS $(100-500 \mu \mathrm{g} / \mathrm{ml})$, DPPH $(0.1 \mathrm{mM})$ was added and allowed to react in the dark for $30 \mathrm{~min}$. The absorbance was measured at $517 \mathrm{~nm}$ using quercetin $(20-100 \mu \mathrm{g} / \mathrm{ml})$ as the standard and the percentage of inhibition was calculated [24].

\subsection{GC-MS analysis}

Ethanol extract of HS was submitted to Scientific and Technological Research Equipment Center (STREC) (Chulalongkorn University, Thailand) and GC-MS analysis was performed using Agilent 7890 GC system coupled with HP-5MS (5\% Phenyl Methyl Silox) capillary column. The extract was dissolved in ethanol, and $0.5 \mu \mathrm{l}$ was injected into the column for analysis with a total run time of $15 \mathrm{~min}$. The extract's constituents were identified by comparing the obtained spectral patterns with those stored in the National Institute of Standards and Technology (NIST) library.

\subsection{Cell viability assay}

HT-22 cells $\left(2 \times 10^{5}\right.$ cells $)$ were grown in 96 -well plates and pre-treated with various doses of ethanol extract of HS for $2 \mathrm{~h}$ prior to the glutamate $(5 \mathrm{mM})$ treatment and then incubated for $24 \mathrm{~h}$. The cells were washed with PBS after $24 \mathrm{~h}$, and MTT $(1 \mathrm{mg} / \mathrm{ml})$ was added and incubated for $2 \mathrm{~h}$ at $37{ }^{\circ} \mathrm{C}$. Finally, MTT was removed, and the formed formazan crystals were solubilized with dimethyl sulphoxide and the absorbance was measured at $540 \mathrm{~nm}$ [25].

\subsection{Determination of reactive oxygen species (ROS) level and superoxide radical}

The accumulation of intracellular ROS and superoxide radical was assessed quantitatively. Cells were grown in dishes and pre-treated with HS $(5,10 \mu \mathrm{g} / \mathrm{ml})$ for $2 \mathrm{~h}$ and then treated with $5 \mathrm{mM}$ glutamate. For ROS estimation, after the treatment period $(24 \mathrm{~h})$, the medium was removed, washed with PBS, $\mathrm{pH}-$ 7.4 and were incubated with $10 \mu \mathrm{M}$ DCFH-DA for $30 \mathrm{~min}$ at $37^{\circ} \mathrm{C}$ in darkness. Cells were washed with PBS followed by lysis (10 mM Tris, $20 \mathrm{mM}$ EDTA, $0.25 \%$ TritonX-100; $\mathrm{pH}-8.0)$ and the fluorescence was measured at $480 \mathrm{~nm}$ (Excitation) and $535 \mathrm{~nm}$ (Emission) using EnSpire Multimode Plate Reader (PerkinElmer, Waltham, MA, USA) [25]. For imaging, cells after staining with DCFH-DA dye were washed twice with PBS buffer and imaged under Confocal microscope with the excitation and emission at 480 and $535 \mathrm{~nm}$ respectively. For superoxide radical measurement, cells after treatment were incubated with $5 \mu \mathrm{M}$ MitoSOX for $10 \mathrm{~min}$ and the fluorescence intensity was measured using plate reader with excitation and emission at 510 and $580 \mathrm{~nm}$ respectively [26].

\subsection{Measurement of glutathione}

HT-22 cells were treated as explained earlier, washed with ice-cold PBS (pH-7.4), and lysed using lysis buffer ( $\mathrm{pH}-8.0)$. The lysates were centrifuged at $10000 \mathrm{rpm}$ for $15 \mathrm{~min}$ at $4^{\circ} \mathrm{C}$ and supernatants were stored at $-80^{\circ} \mathrm{C}$ until further use. Protein estimation was performed for all the samples by Bradford's method. For glutathione estimation, cell lysate (100 $\mu \mathrm{g}$ protein) from different experimental groups 
was taken, precipitated with an equal volume of $5 \%$ TCA and centrifuged at $4200 \mathrm{rpm}$ for $10 \mathrm{~min}$. The pellets were suspended in PBS, followed by the addition of $0.6 \mathrm{mM}$ DTNB. The reaction mixture was incubated for $5 \mathrm{~min}$ at room temperature, and the absorbance was measured at $412 \mathrm{~nm}$ with glutathione $(10-50 \mu \mathrm{M})$ as standard. The results are expressed as $\mu \mathrm{M}$ of $\mathrm{GSH} / \mathrm{mg}$ of protein [27].

\subsection{Determination of mitochondrial membrane potential (MMP)}

HT-22 cells were treated as explained earlier and after which, cells were incubated with Rh $123(5 \mu \mathrm{M})$ for $30 \mathrm{~min}$ at $37^{\circ} \mathrm{C}$. The cells were washed with PBS, and the fluorescence intensity was measured with the excitation and emission wavelength of 480 and $530 \mathrm{~nm}$, respectively. For the visualization of change in MMP, cells after treatment were imaged with Confocal microscope [28].

\subsection{Acridine orange/Ethidium bromide $(A O / E t B r)$ dual staining}

Cells were grown in Petri dishes and treatment was done as explained earlier. After $24 \mathrm{~h}$, cells were washed with PBS and incubated with $10 \mu \mathrm{g} / \mathrm{ml}$ $\mathrm{AO} / \mathrm{EtBr}$ solution $(1: 1 \mathrm{v} / \mathrm{v})$ for $10 \mathrm{~min}$, imaged under Axio Observer A1 fluorescence microscope (Carl Zeiss, Jena, Germany), and the images were processed using ImageJ [28].

\subsection{Real Time PCR analysis}

Total RNA was isolated from treated cells using the standard Trizol procedure according to the manufacturer's recommendations. RNA concentration was quantified and $1000 \mathrm{ng}$ RNA was reverse-transcribed using oligodT primer and Accupower RT Premix (Bioneer, Korea). Green Star PCR Master Mix (Bioneer, Korea) was used for performing real-time PCR (qPCR) analysis and amplified using genespecific primers (Table S1). The obtained results were normalized to GAPDH expression as the endogenous control [25].

\subsection{Molecular docking analysis}

The 3D structures of proteins NMDAR (3QEL), Calpain (2R9C) and GSK-3 $\beta$ (1Q5K) were taken from the PDB databank. The compounds obtained from GC-MS analysis were extracted from the Pubchem database and were considered for molecular docking analysis using DockThor. Memantine, SNJ-1945, and LY2090314 are used as reference compounds for NMDAR, calpain-1, and GSK-3 $\beta$ respectively. The binding pockets and interaction of the ligands with the protein were identified through a grid-based docking approach using MMFF94S force field and the binding energies of the docked poses were calculated for the screening of compounds with inhibitory potential [29].

\subsection{Theoretical prediction of blood brain barrier (BBB) permeability of compounds}

As the identified compounds showed high binding affinity with the target proteins, the ability of the phytochemicals to cross BBB was evaluated using the free online software SwissADME (http://www.swissadme.ch/) [30].

\subsection{Western blot analysis}

Following treatment, the cells were collected, washed with PBS and proteins were obtained by lysis with RIPA buffer. Cell lysates (50 $\mu \mathrm{g}$ of protein) were electrophoresed on $12 \%$ SDS gels followed by transfer to polyvinylidene difluoride (PVDF) membranes. The membrane was blocked in 5\% non-fat milk for overnight followed by $6 \mathrm{~h}$ incubation with corresponding primary antibodies (JNK (1:2000), pJNK (1:2000), p38 (1:2000), p-p38 (1:2000), LC-3B (1:2000), EAAT-3 (1:2000), $\beta$-actin (1:5000)) followed by $2 \mathrm{~h}$ incubation with anti-rabbit IgG-HRP linked secondary anti-body (1:10000). The bands were developed with ECL detection reagent using autoradiography films and Kodak processing chemicals and quantified with ImageJ software [14].

\subsection{C. elegans strains and culture conditions}

Wild type strain N2 (Bristol), daf-16 mutant CF1038, and daf-2 mutant CB1370 and the bacterial food source $E$. coli OP50 were procured from Caenorhabditis Genetics Centre. C. elegans strain was routinely maintained at $15{ }^{\circ} \mathrm{C}$ in nematode growth medium (NGM) agar plate using standard protocol [12]. 


\subsection{Lifespan assay}

Analysis of lifespan of C. elegans strains and protective dose of HS was performed in liquid media as explained below. Age synchronized young adult nematodes (10 numbers/well) were seeded in a 24well plate and treated with HS $(10-100 \mu \mathrm{g} / \mathrm{ml}$ for wild type; $20-40 \mu \mathrm{g} / \mathrm{ml}$ for mutants). The number of animals alive was scored under microscope for every $24 \mathrm{~h}$ and was plotted [12].

\subsection{Fluorescence imaging of Lipofuscin accumulation}

Worms were treated with varying concentrations of HS $(20-40 \mu \mathrm{g} / \mathrm{ml})$ for 5 days with $E$. coli OP50 fed as the control. The worms were washed with M9 buffer after the treatment period, placed on glass slide with a drop of sodium azide and visualized under confocal microscope. Images were processed using Image $\mathrm{J}$ and the relative fluorescence was represented as arbitrary units (AU) [12].

\subsection{Real Time PCR analysis}

Nematodes were treated as explained earlier, and after the treatment period total RNA was isolated using Trizol kit (Invitrogen, Carlsbad, CA, USA). Real Time PCR analysis was performed as explained in section 2.10 with gene specific primers (Table-S1) and actin as the internal control [12].

\subsection{Statistical analysis}

All the experiments were done in triplicates and expressed as Mean \pm SD. One-way ANOVA (SPSS 17, SPSS Inc., Chicago, IL) followed by Duncan's post hoc test was performed to compare control vs treated and $p<0.05$ was considered as significant.

\section{Results}

\subsection{Antioxidant property of $H S$ and identification of compounds}

DPPH assay that offers a simplified version to elucidate antioxidant properties, shows that the free radical scavenging of ethanolic extract of HS occurred in a concentration-dependent manner. The extract showed $94.6 \%$ inhibition at $500 \mu \mathrm{g} / \mathrm{ml}$ concentration at an IC50 value of $95.07 \pm 1.44 \mu \mathrm{g} / \mathrm{ml}$ (Fig. 1A) indicating the antioxidant potential. GC-MS analysis was performed for the extract to identify the phytochemicals responsible for the antioxidant properties (Fig. 1B). The extract showed the presence of 19 compounds including 5-hydroxymethylfurfural, 2,4Di-tert-butylphenol, ethyl linoleate and oleamide, which have antioxidant properties (Table S2).

\subsection{HS extract restored the cell viability in HT-22 cells}

Cytotoxic effect of HS extract was analyzed by MTT assay. To check the effect of HS extract, HT-22 cells were treated with varying range of the extract (20 $-100 \mu \mathrm{g} / \mathrm{ml}$ ) for $24 \mathrm{~h}$. The tested concentrations did not show any significant cytotoxic effects on the cells and maintained the cell viability (Fig. 2A). The cytotoxic dose was first identified by treatment of various concentrations of glutamate $(1-10 \mathrm{mM})$ with HT-22 cells (Fig. S1). Treatment with glutamate $(5 \mathrm{mM})$ for $24 \mathrm{~h}$, showed a significant $(p<0.05)$ reduction in cell viability to $49.7 \pm 0.7 \%$. However, pre-treatment with extract $(10 \mu \mathrm{g} / \mathrm{ml})$ showed a significant increase in cell viability $(94.8 \pm 6.6 \%)$ (Fig. 2B). Based on the observed results, $5,10 \mu \mathrm{g} / \mathrm{ml}$ of HS extract were used for further experimental analysis.

\subsection{HS extract reduced glutamate-induced ROS and superoxide radical level in HT-22 cells}

As oxidative stress is a prime mediator in glutamate-induced toxicity, ROS level was measured both qualitatively and quantitatively. Exposure to HT22 cells for $24 \mathrm{~h}$ caused a significant increase in the DCF-DA fluorescence (1859.4 \pm 15.9 DCFDA fluorescence intensity) (Fig. 3A). This can also be observed by the increase in fluorescent intensity in glutamate-treated group in confocal microscopic images (Fig. S2B). However, in a dose-dependent manner, pre-treatment with HS extract significantly reduced ROS level $(985.9 \pm 18.7,740.6 \pm 11.5$ for 5 , $10 \mu \mathrm{g} / \mathrm{ml}$ ) when compared to glutamate treated group indicating the antioxidant potential (Fig. 3A, Fig. S2C-E). In addition, quantitative analysis revealed that the level of superoxide radical was increased upon glutamate treatment $(318 \pm 15.52 \mathrm{MitoSOX}$ fluorescence intensity), whereas HS extract significantly reduced the level in a dose-dependent manner indicating the antioxidant activity (Fig. 3B). 
A

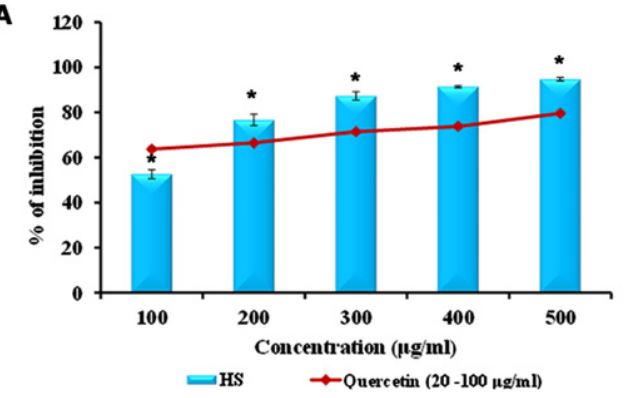

B

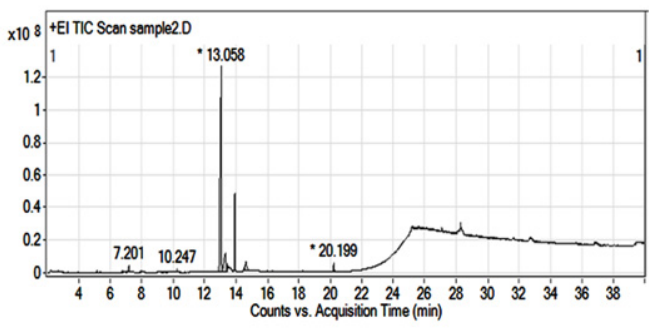

Fig. 1. (A) Free radical scavenging of HS $(100-500 \mu \mathrm{g} / \mathrm{ml})$ in comparison to quercetin. (B) GC-MS spectral pattern of ethanol extract of HS (* significance at $p<0.05 ; n=3)$.
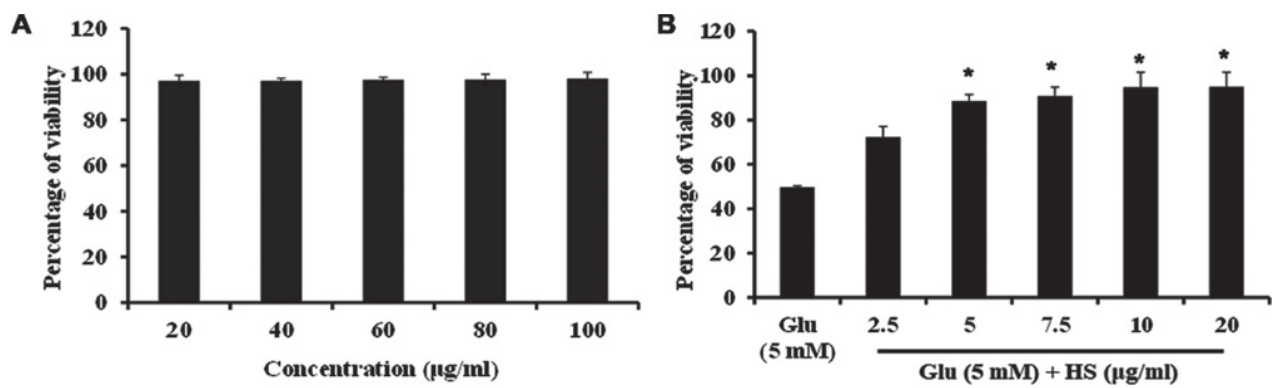

Fig. 2. (A) Effect of varying concentrations of HS in HT-22 cells (B) Protective effect of HS on glutamate induced toxicity. (Significance at $p<0.05 ; *$ Glutamate vs HS treated; $n=3$ ).

A

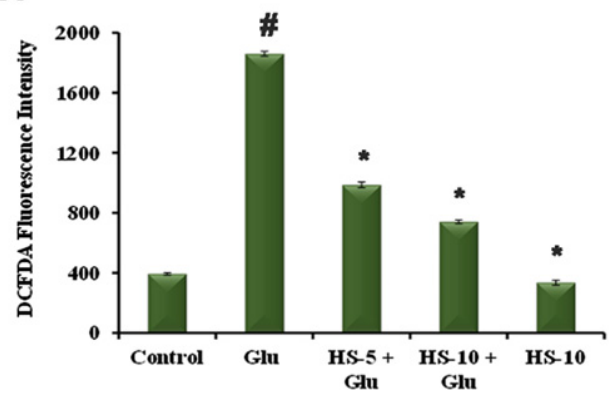

B

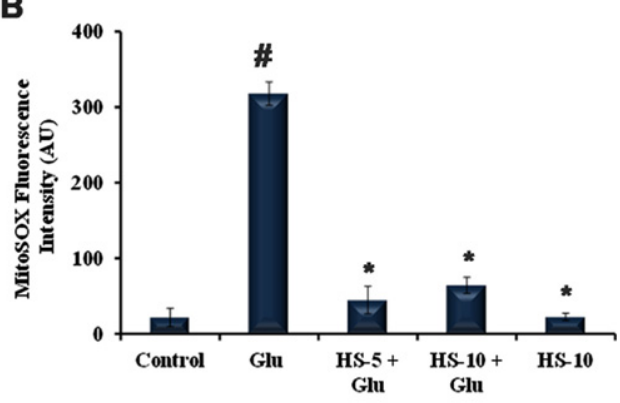

Fig. 3. Quantitative analysis of (A) ROS measurement by DCFHDA fluorescence (B) Superoxide radical measurement by MitoSOX fluorescence (Significance at $p<0.05$; \# Control vs Glutamate; * Glutamate vs HS treated; $n=3$ ).

\subsection{HS extract induced the expression of} glutamate transporters to restore the level of glutathione

As glutamate toxicity interferes with glutamate transporters (EAAT-3, GLT-1) to hamper glutathione synthesis and inhibit the export of excess glutamate in the synaptic cleft, the expression of the transporters was analyzed. Transcriptional studies show that the glutamate transporter GLT-1 $(0.61 \pm 0.21$ fold) was significantly downregulated, indicating the hampering of excess glutamate transport from the synaptic cleft (Fig. 4A). Likewise, protein expression studies show that EAAT-3 $(0.56 \pm 0.13$ fold $)$ is significantly downregulated in the glutamate treated group (Fig. 4B, C). However, HS pre-treatment induced the expression of glutamate transporters to bring back the homeostatic condition in cells. Further, as glutamate transporters are involved in glutathione synthesis, the level of non-enzymatic antioxidant, glutathione was analyzed. Glutamate treatment significantly reduced the level of glutathione $(28.8 \pm 3.1 \mu \mathrm{M} \mathrm{GSH} / \mathrm{mg}$ protein) when compared to control. A reversal in the effect in a dose-dependent manner was observed upon pre-treatment with HS (Fig. 4D), which could be corroborated with the increased expression of EAAT-3. 
A

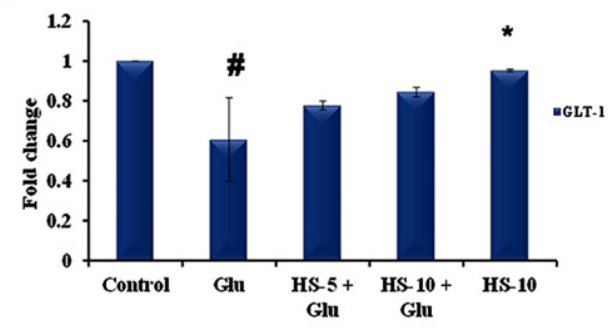

D

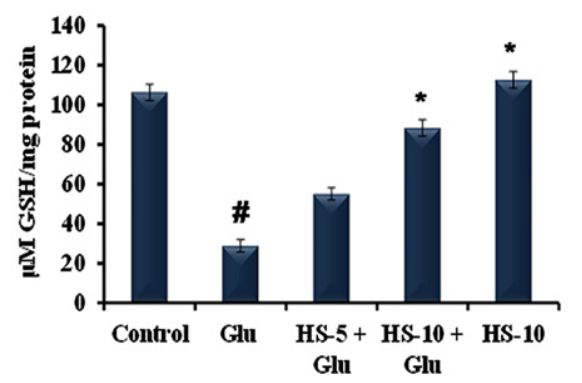

B

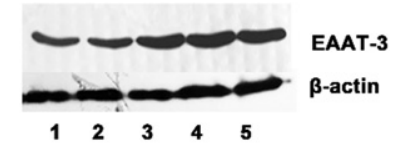

C
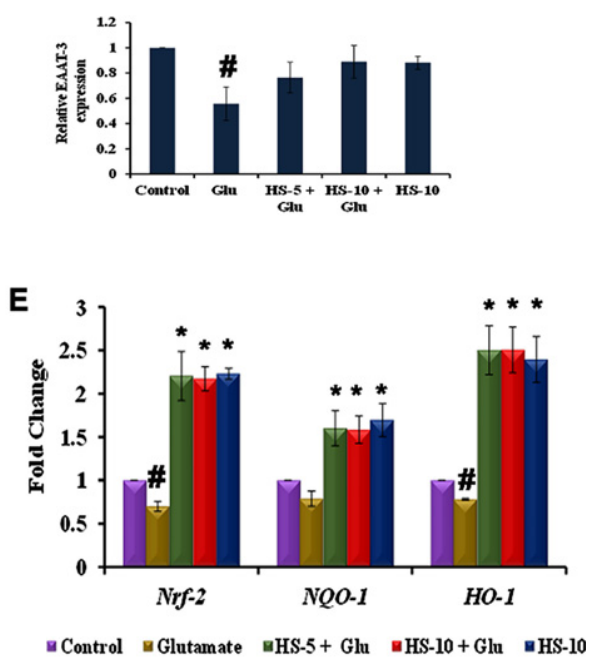

Fig. 4. (A) Transcriptional regulation of glutamate transporter GLT-1 by HS (B) Western blot analysis of EAAT-3 (Lane: 1- Control; 2 Glutamate; 3- HS-5 + Glutamate; 4- HS-10+Glutamate; 5- HS-10) (C) Quantification of EAAT-3 expression (D) Effect of HS on nonenzymatic antioxidant glutathione (E) Transcriptional regulation of antioxidant dependent genes by HS (Significance at $p<0.05$; \# Control vs Glutamate; * Glutamate vs HS treated; $n=3$ ).

The results indicate that extract could act on glutamate transporters to facilitate glutathione synthesis and induce glutamate transport, thereby reducing toxicity.

In addition, glutamate treatment also showed a significant $(p<0.05)$ downregulation in the expression of $N r f-2(0.7 \pm 0.05$ fold $), N Q O-1$ ( $0.79 \pm 0.08$ fold $)$ and $H O-1$ ( $0.78 \pm 0.01$ fold), when compared to the control. Pre-treatment with both the concentration of HS extract significantly upregulated the expression of all the tested genes compared to the glutamate group. Further, significant upregulation of the genes was also observed in HS alone treated group indicating the extract's ability to induce antioxidant mechanism in cell (Fig. 4E).

\subsection{HS extract restored mitochondrial membrane potential in HT-22 cells against glutamate toxicity by inhibiting the expression of Cyclophilin-D (Cyp-D)}

Mitochondrial permeability transition pore (mPTP) formation coupled with increased Cyp-D expression, and change in mitochondrial membrane potential (MMP) is regarded as a consequent phenomenon of oxidative stress. Glutamate treatment showed a significant increase in the expression of Cyp-D (2.03 \pm 0.2 fold) (Fig. 5G) with a reduction in mitochondrial membrane potential $(40.3 \pm 1.4 \%)$ (Fig. 5F), which could also be observed with the reduction in fluorescence intensity (Fig. 5B). However, pre-treatment with extracts showed significant downregulation of Cyp-D, 1.36, 1.2 fold for 5, $10 \mu \mathrm{g} / \mathrm{ml}$ extract respectively (Fig. 5G). An increase in $\mathrm{Rh} 123$ fluorescence is observed in the extracts treated group (Fig. 5C, D) indicating a reduction in the formation of $\mathrm{MPTP}$ and restoration of MMP.

\subsection{HS extract inhibited Endoplasmic reticulum (ER) stress-associated autophagy induction by glutamate via inhibiting MAPK pathway}

To evaluate ER stress-associated induction of autophagy, the transcriptional regulation of Grp78, calpain-1, GSK-3 $\beta$ and autophagy related genes (Beclin-1, ATG-5, ATG-7), proteins (LC3-II, p38/p$\mathrm{p} 38, \mathrm{JNK} / \mathrm{p}-\mathrm{JNK}$ ) were evaluated. Upon glutamate toxicity, gene expression of Grp-78, calpain-1 and $G S K-3 \beta$ were upregulated, implying ER-stress (Fig. 6A), followed by the activation of MAPK pathway, which could be identified by a significant increase in the ratio of p-p38/p38 (1.75 \pm 0.36 fold), 

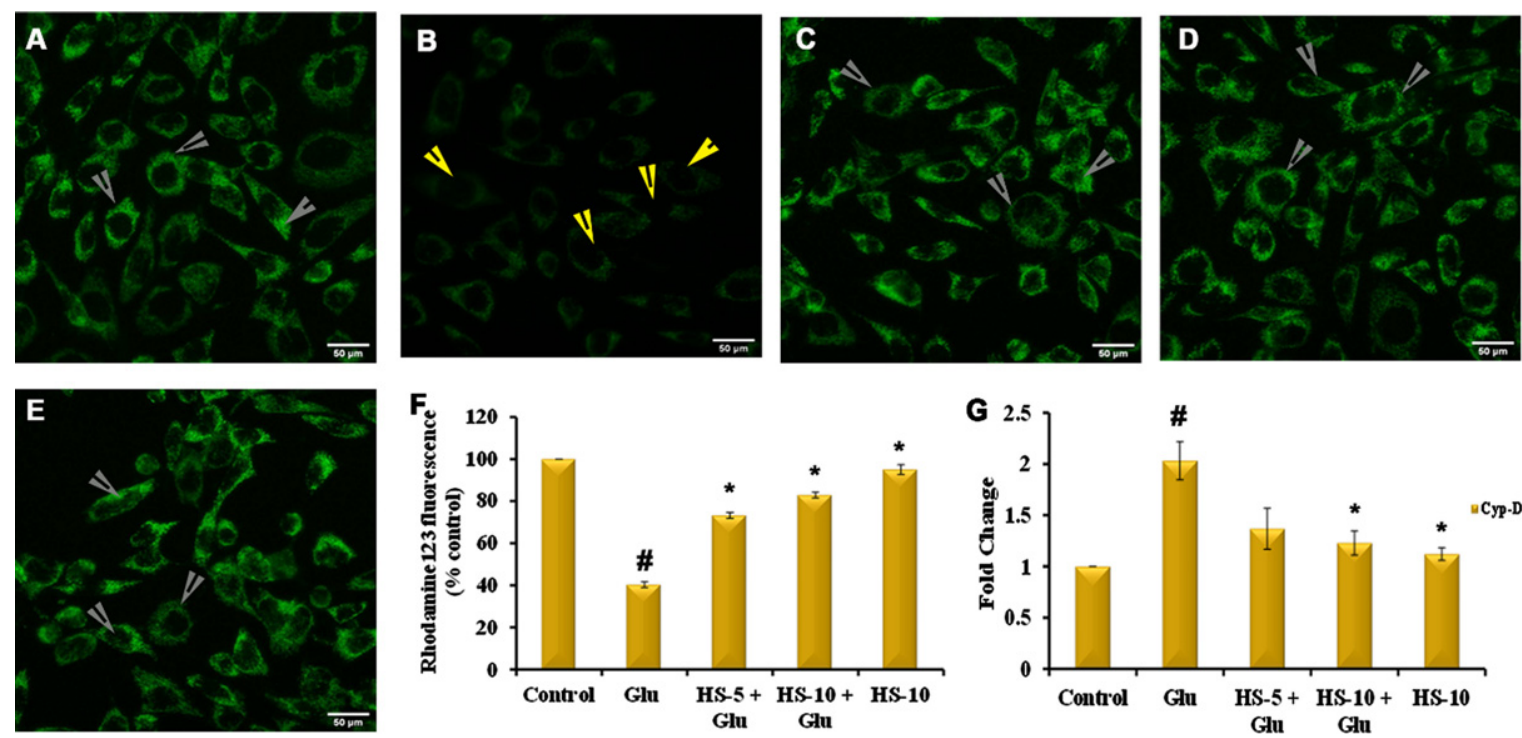

Fig. 5. Confocal microscopic examination of alteration in mitochondrial membrane potential by HS (A) Control (B) Glutamate (5 mM) (C) HS-5 + glutamate (D) HS-10 + glutamate (E) HS-10 (Yellow arrows indicating loss of MMP and white arrows indicating restoration of MMP) (F) Quantitative analysis of Rh 123 fluorescence (G) Transcriptional regulation of Cyp-D by HS (Significance at $p<0.05$; \# Control vs Glutamate; * Glutamate vs HS treated; $n=3$; scale bar $-50 \mu \mathrm{m}$ ).

p-JNK/JNK (1.75 \pm 0.25 fold) expression (Fig. 6D, E). Further, the gene expression of Beclin-1, ATG-5, $A T G-7$ (Fig. 6A) were significantly $(p<0.05)$ upregulated coupled with induced protein expression of LC3-II (a marker of the autophagic process) indicating induction of autophagy through ER-stress dependent MAPK mechanism (Fig. 6B, C). Pretreatment with HS extract ameliorated ER stress by reducing the expression of Grp-78 and suppressed MAPK pathway activation. In addition, the expression of autophagic genes (Beclin-1, ATG-5, ATG-7) and protein (LC3-II) were significantly downregulated indicating the suppression of autophagy (Fig. 6A-C). The results show that HS extract inhibits autophagy induced by glutamate and protects HT-22 cells by suppressing MAPK pathway.

\subsection{Compounds of HS exhibited inhibitory activity against the key targets of the glutamate excitotoxicity pathway and could cross $B B B$}

The interaction between key targets (NMDAR, Calpain-1, GSK-3 $\beta$ ) involved in glutamate toxicity was studied with the compounds identified from HS extract from GC-MS analysis by molecular docking studies. The top five hits against each of the protein NMDAR, Calpain-1, GSK-3 $\beta$ displaying different types of interactions including hydrogen bond, alkyl bond, $\pi-\pi$ bond, $\pi-$ alkyl bond is represented in Figs. 7, 8, and 9 respectively. The binding scores and interaction were identified and compared with that of the reference compounds memantine (NMDAR), SNJ-1945 (Calpain-1), LY2090314 (GSK-3 $\beta)$. Though the tested ligands exhibit different interaction sites than the reference compounds, an almost equal or higher binding score is observed indicating their ability to strongly bind with the target protein. For NMDAR, the top 5 hits ethyl linoleate $(-7.712 \mathrm{kcal} / \mathrm{mol})$, palmitic acid $(-7.569 \mathrm{kcal} / \mathrm{mol})$, oleamide $(-7.323 \mathrm{kcal} / \mathrm{mol})$, 5 -methylfurfural $(-7.244 \mathrm{kcal} / \mathrm{mol})$ and ethyl palmitate $(-7.229 \mathrm{kcal} / \mathrm{mol})$ exhibited higher binding score compared with memantine $(-6.757 \mathrm{kcal} / \mathrm{mol})$. Docking against calpain-1 showed that only ethyl linoleate exhibited a higher binding score $(-8.328 \mathrm{kcal} / \mathrm{mol})$ when compared to the reference compound SNJ-1945 (-8.195 kcal $/ \mathrm{mol})$, which is followed by oleamide, ethyl palmitate, palmitic acid and 2-(diethoxymethyl)furan with a binding score of $-7.836,-7.733,-7.158$, and $-6.937 \mathrm{kcal} / \mathrm{mol}$. In the case of $G S K-3 \beta, \mathrm{LY} 2090314$ $(-7.892 \mathrm{kcal} / \mathrm{mol})$ showed highest binding score and is closely followed by the ligands ethyl linoleate $(-7.539 \mathrm{kcal} / \mathrm{mol})$, ethyl palmitate $(-7.388 \mathrm{kcal} / \mathrm{mol})$, 2-(diethoxymethyl)furan $\quad(-7.195 \mathrm{kcal} / \mathrm{mol}), \quad 5$ methylfurfural $(-6.973 \mathrm{kcal} / \mathrm{mol})$ and diethyl succinate $(-6.916 \mathrm{kcal} / \mathrm{mol})$. The results indicate that 


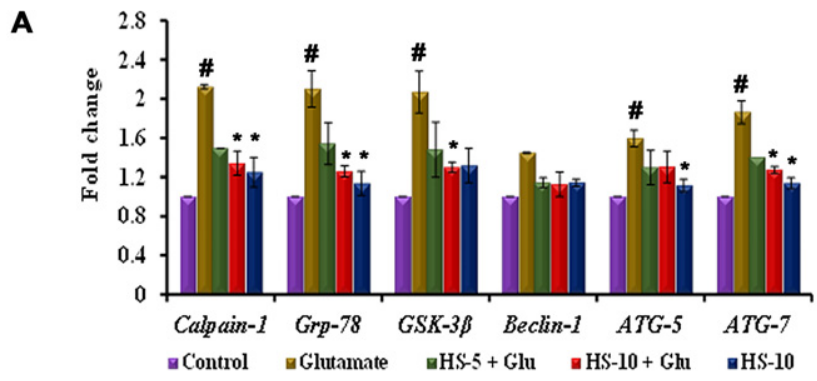

B

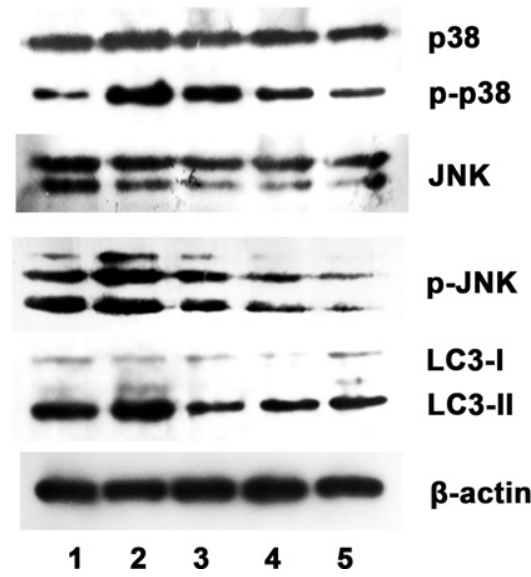

C
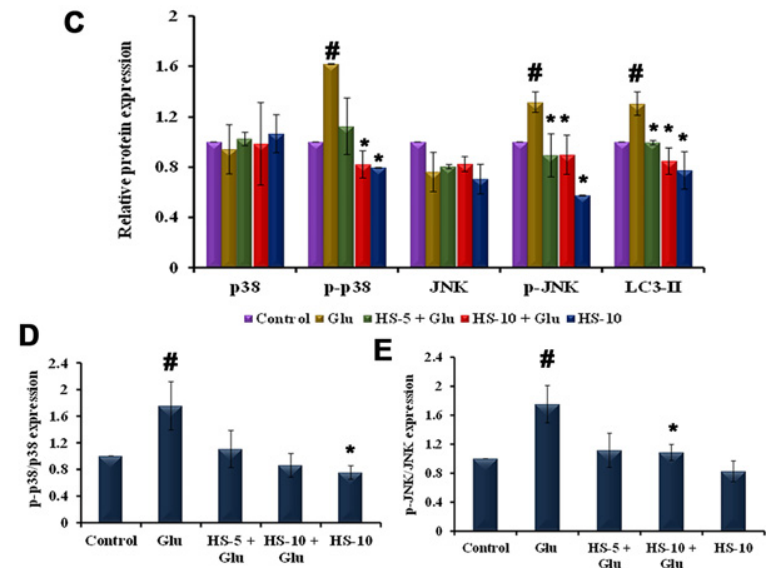

Fig. 6. (A) Transcriptional regulation of ER stress, autophagy-associated genes by HS (B) Western blot analysis of proteins involved in MAPK (p38/p-p38, JNK/p-JNK) pathway and autophagy (LC3-II) (Lane: 1- Control; 2- Glutamate; 3- HS-5 + Glutamate; 4- HS-10 + Glutamate; 5HS-10) (C) Quantification of relative expression of proteins involved in MAPK (p38/p-p38, JNK/p-JNK) pathway and autophagy (LC3-II) (D) Quantification of p-p38/p38 expression (E) Quantification of p-JNK/JNK expression (Significance at $p<0.05$; \# Control vs Glutamate; * Glutamate vs HS treated; $n=3$ ).

the HS extract compounds can inhibit the key targets involved in glutamate excitotoxic pathway and thus protect cells from cell toxicity.

Further, BBB permeability of the compounds was predicted using SwissADME. The results showed that out of the 19 compounds, 10 compounds were predicted to be BBB permeant (Table S3). Interestingly, oleamide, palmitic acid, diethyl succinate, 2-(diethoxymethyl) furan and 5-methylfurfural, which showed high binding affinity with the protein targets were found to be permeant indicating the compounds could transverse BBB and exert their effectiveness to protect the cells from toxicity.

\subsection{HS extract exhibited anti-apoptotic effect against glutamate-induced toxicity}

The anti-apoptotic effect of HS extract was evaluated by acridine orange/ethidium bromide dual staining. As evidenced from the results glutamate treatment showed increased orange-red staining, a characteristic phenomenon of an apoptotic cell (Fig. 10B) indicating glutamate-induced autophagy and increased expression of JNK results in apoptosis. However, green staining indicates live cells showing a reversal in effect upon pre-treatment with HS (Fig. 10C-E), implying the extract could ameliorate glutamate-induced apoptosis in HT-22 cells.

\subsection{HS extract extended the lifespan of $C$. elegans}

To check the lifespan extension ability, wild type strain was treated with various concentrations (10 $-100 \mu \mathrm{g} / \mathrm{ml}$ ) of extract. HS treatment significantly $(p<0.05)$ increased the survival rate of nematodes when compared to the control at the tested concentrations. Maximum survival rate was observed in HS treatment at the concentrations ranging from $20-40 \mu \mathrm{g} / \mathrm{ml}(24,25,25$ days $)$ when compared to control, which survived for 21 days (Fig. 11A, B). 
A

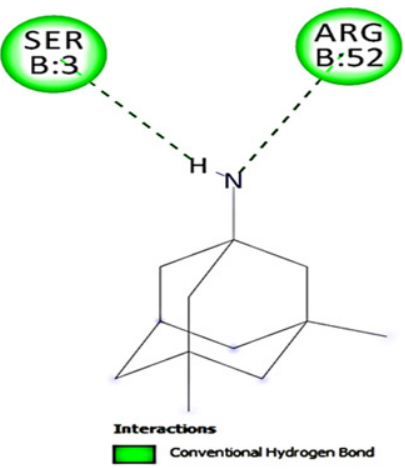

C

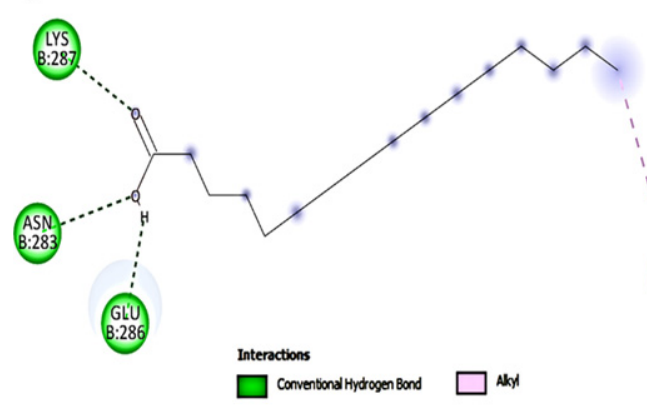

E $\begin{gathered}\text { PHE } \\ \text { B:273 }\end{gathered}$

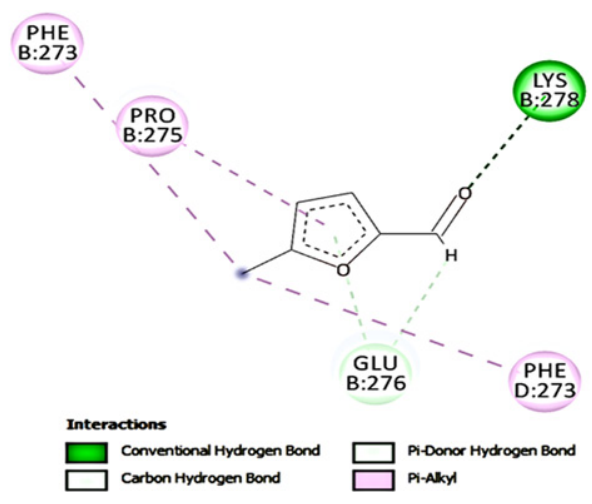

B
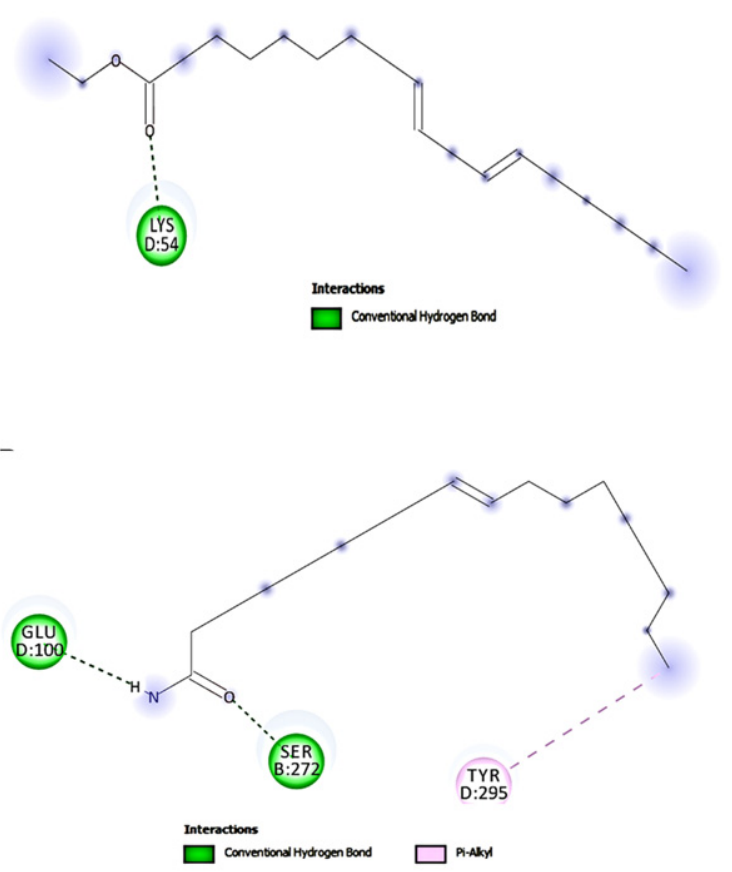

$\mathbf{F}$

LE:

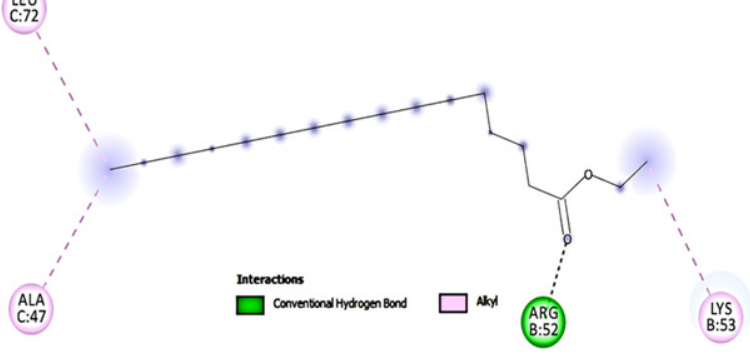

Fig. 7. Molecular docking analysis of top 5 compounds in HS against NMDAR (A) Memantine (B) Ethyl linoleate (C) Palmitic acid (D) Oleamide (E) 5-methylfurfural (F) Ethyl palmitate.

The results show that HS has the ability to extend the lifespan and increase the survival rate.

\subsection{HS extract improved the healthspan of nematodes}

A significant reduction in the level of lipofuscin, an indicator of aging was observed in $\mathrm{HS}(20-40 \mu \mathrm{g} / \mathrm{ml})$ treated group when compared to the control indicating the slowing down of aging process (Fig. 12A-E). Further, HS treatment $(20-40 \mu \mathrm{g} / \mathrm{ml})$ showed a significant $(p<0.05)$ modulation in the expression of positive (egl-8, egl-30) and negative (dgk-1, goa-1, col-19) regulators of healthspan when compared to the control indicating that HS extract could improve the healthspan of the nematodes (Fig. 12F).

\subsection{HS induced antioxidant mechanism and extended lifespan via DAF-16 dependent pathway}

HS extract treatment showed a significant $(p<0.05)$ upregulation of the antioxidant gene $s k n-1$ in a dose-dependent manner indicating the antiox- 
A

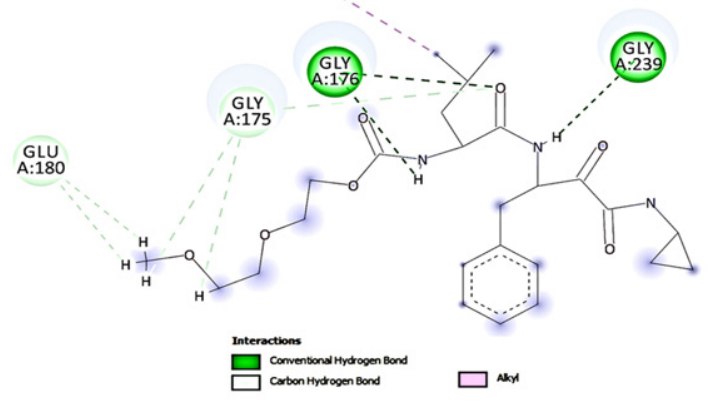

C

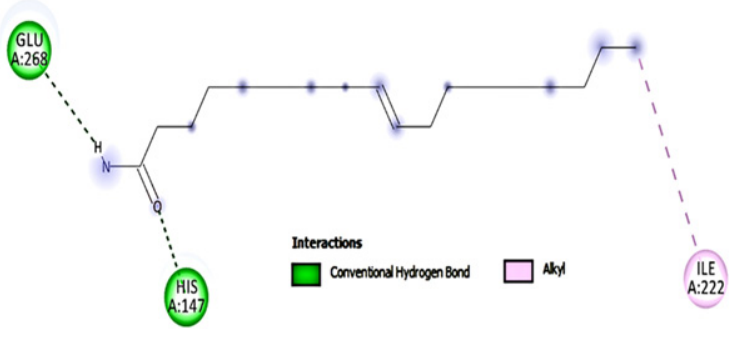

$\mathbf{E}$

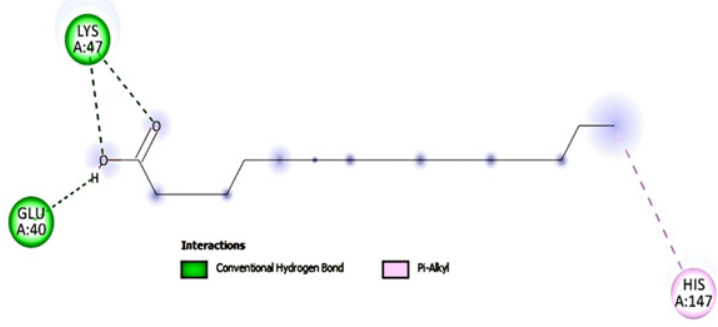

B

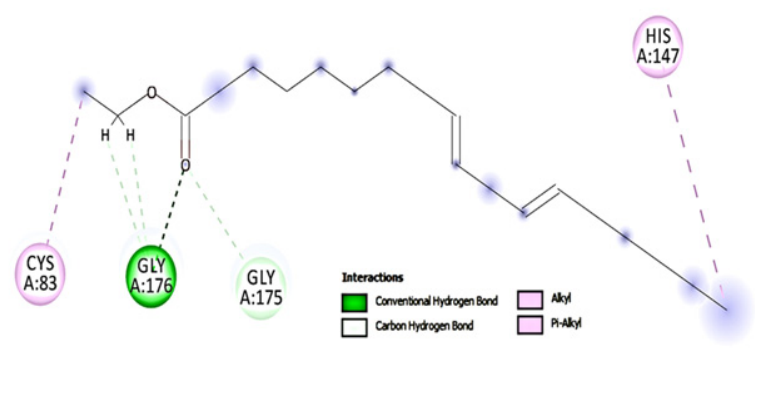

D

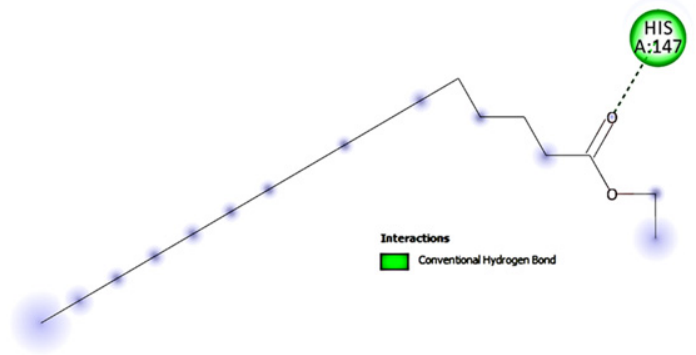

$\mathbf{F}$

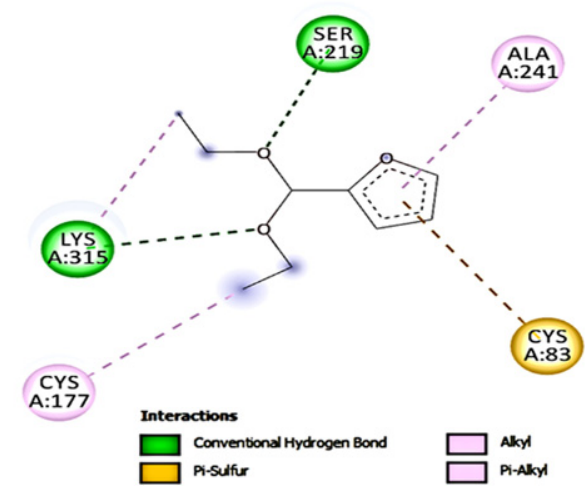

Fig. 8. Molecular docking analysis of top 5 compounds in HS against Calpain-1 (A) SNJ-1945 (B) Ethyl linoleate (C) Oleamide (D) Ethyl palmitate (E) Palmitic acid (F) 2-(diethoxymethyl)furan.

idant potential of the extract (Fig. 13A). Further upon treatment with HS, a significant downregulation of daf-2, one of the key players in DAF-16 pathway was also observed when compared to the control suggesting the extract acts through DAF-16-dependent mechanism (Fig. 13A). This was further validated by using DAF-16, DAF-2 mutants. HS extract treatment to both the mutant worms did not exhibit any significant increase in the lifespan compared to the control indicating the lifespan extension property of HS extract is mediated through DAF-16-dependent mechanism (Fig. 13B-E).

\section{Discussion}

The excitatory neurotransmitter, glutamate at higher concentration in the synaptic cleft shows neurotoxicity and leads to the development of neurodegenerative diseases including $\mathrm{AD}$. In the present study, the neuroprotective efficacy of calyces of Hibiscus sabdariffa was evaluated against glutamateinduced toxicity in HT-22 cells. Pioneering studies have reported that glutamate-induced neurotoxicity is caused by the aberrant formation of ROS, mitochondrial dysfunction, ER stress coupled with influx of $\mathrm{Ca}^{2+}$ ions leading to the activation of calpain, 
A
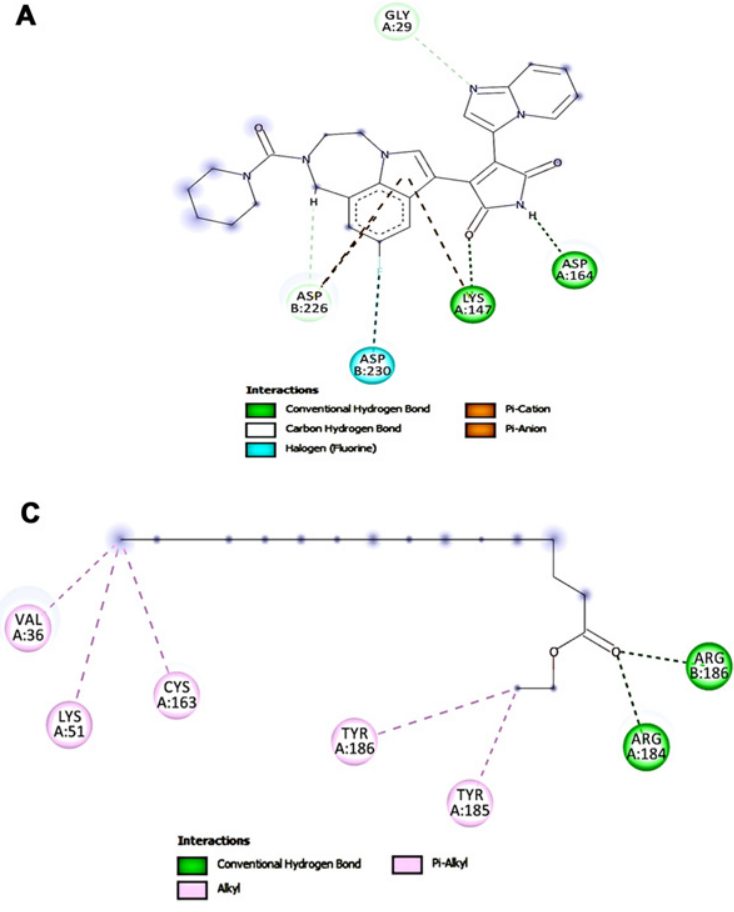

E

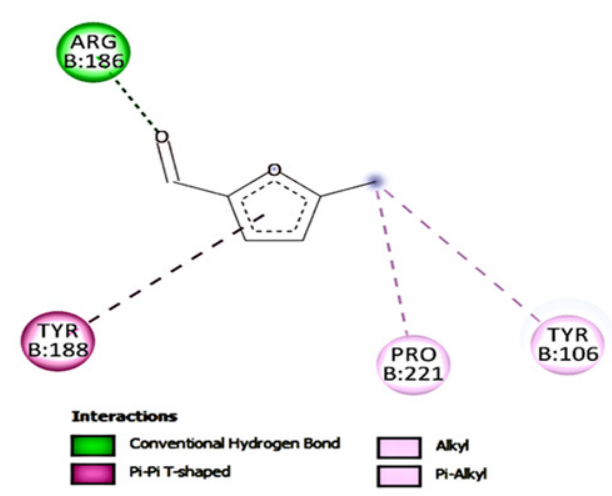

B

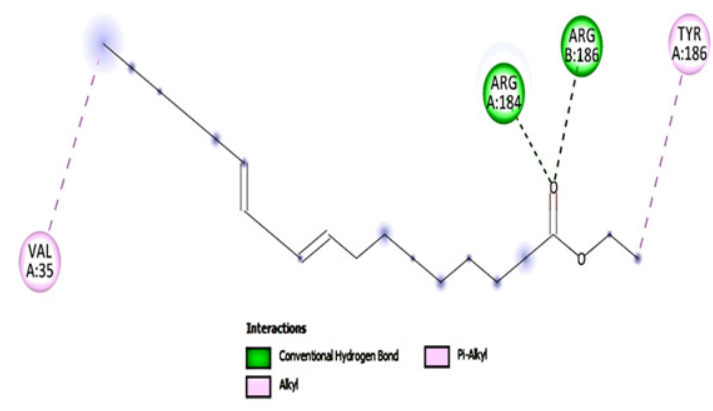

D
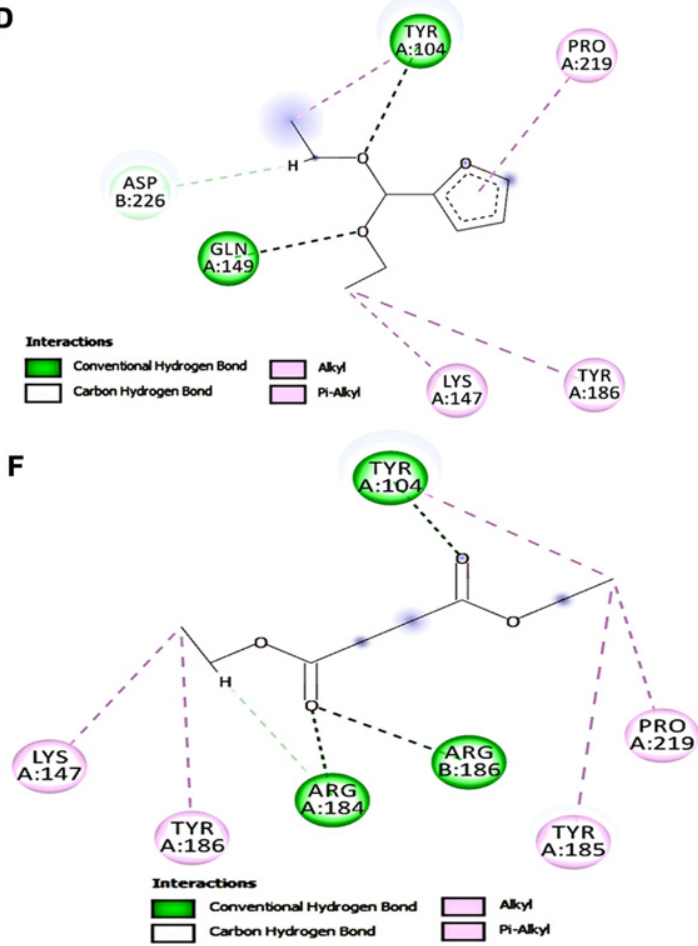

Fig. 9. Molecular docking analysis of top 5 compounds in HS against $G S K-3 \beta$ (A) LY2090314 (B) Ethyl linoleate (C) Ethyl palmitate (D) 2-(diethoxymethyl)furan (E) 5-methylfurfural (F) Diethyl succinate.

and activation of MAPK's [31, 32]. In accordance with the reports, glutamate $(5 \mathrm{mM})$ showed a significant reduction in cell viability in HT-22 cells. Our study shows that ethanol extract of HS significantly counteracted the toxicity exerted by glutamate in a dose-dependent manner.

As reported, glutamate's toxicity is mainly due to the generation of ROS and subsequent damages occurring in the biological macromolecules. In concomitant to the reports, glutamate treatment exerted oxidative stress in HT-22 cells, which is evident from the generation of ROS. Glutamate-induced oxidative stress also hampers cellular defense mechanism by depleting the non-antioxidant enzyme glutathione via blocking cysteine/glutamate exchange system [33]. The excitatory amino acid transporter-3 (EAAT3)/excitatory amino acid carrier-1 (EAAC-1) helps attenuate oxidative stress by the re-uptake of cysteine for glutathione synthesis. It has been reported that more than EAAT-1/GLAST-1 and EAAT-2/GLT1, EAAT-3 binds and uptake cysteine efficiently, which could be evident from the studies in EAAT3 knock out mice [34]. Furthermore, a significant downregulation of these transporters is observed in neurodegenerative disease conditions, implicating defect in the glutamate uptake and subsequent 

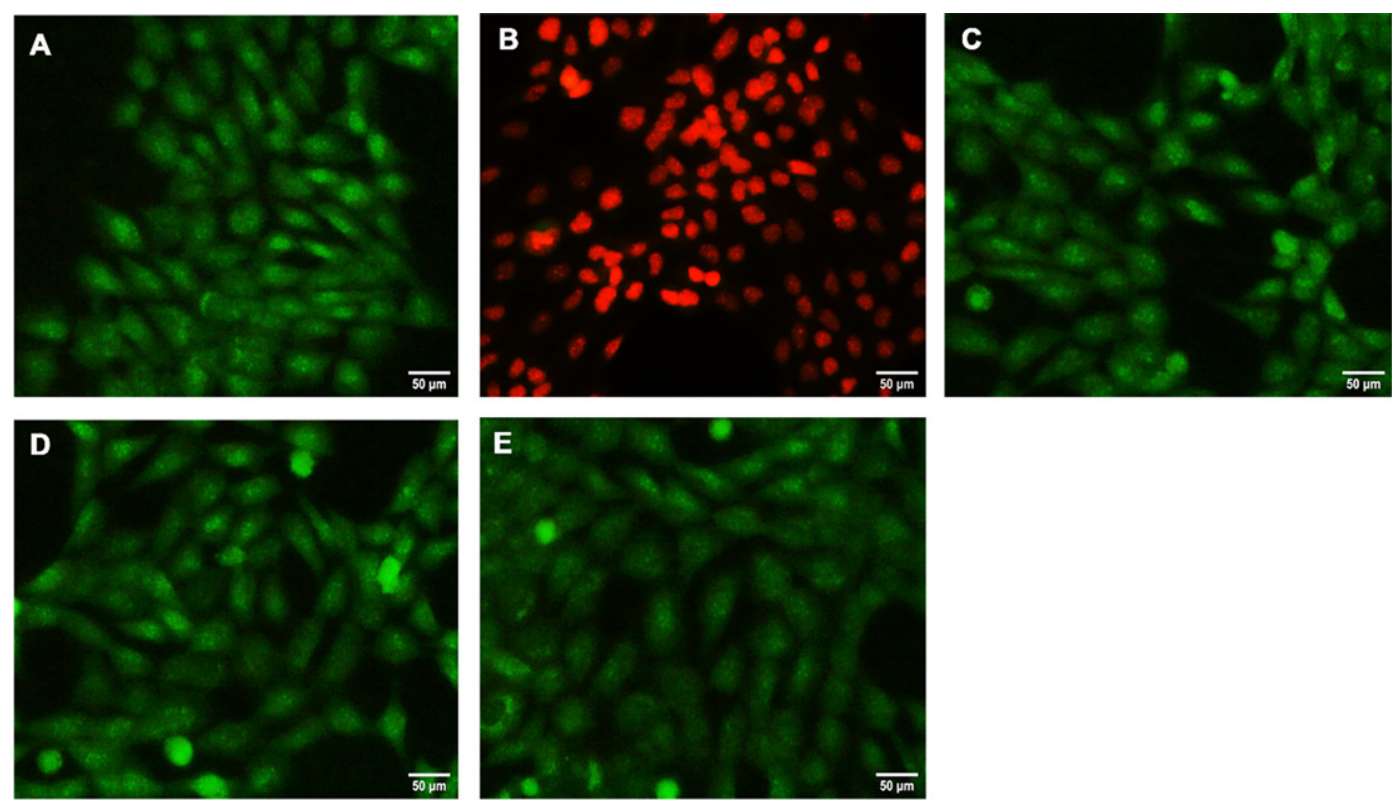

Fig. 10. Fluorescent microscopic examination of inhibition of apoptosis by HS (A) Control (B) Glutamate (5 mM) (C) HS-5 + glutamate (D) HS-10 + glutamate (E) HS-10. Green staining indicates live cells and orange red staining denotes apoptotic cells.

A

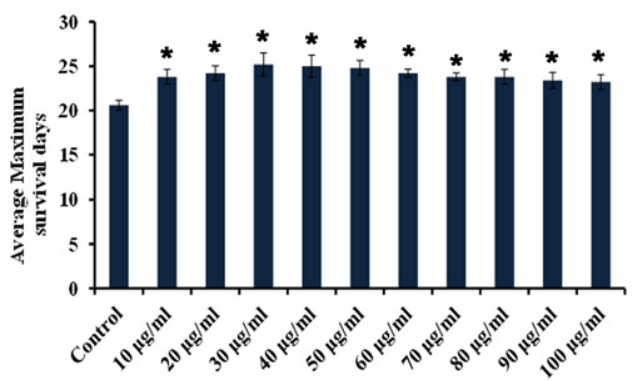

B

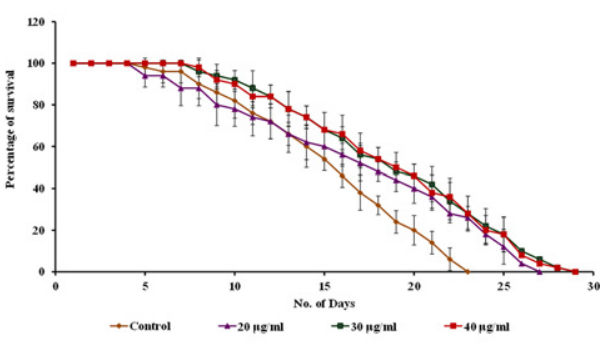

Fig. 11. (A) Maximum lifespan of wild type nematodes upon treatment with varying concentration (10 - $100 \mu \mathrm{g} / \mathrm{ml})$ of $\mathrm{HS}$ extract (B) Life span assay of wild type nematodes upon treatment with HS extract $(20-40 \mu \mathrm{g} / \mathrm{ml})(*$ significant level at $p<0.05)$.

toxicity $[35,36]$. The antioxidant response elements (ARE), including Nrf-2, HO-1 and NQO-1, which plays important role in protecting the cells from toxic stress insults were also significantly downregulated. Glutamate-induced toxicity also causes mitochondrial dysfunction, accompanied with the mPTP formation and release of apoptotic factors causing neurodegeneration [25]. The opening of mPTP is dependent on Cyp-D, whose aberrant expression is observed in neurodegenerative disorders resulting in dissipation of MMP and causing cell death [37]. Considering that, hampering ROS production, improving the antioxidant status and mitochondrial functions is an essential measure to counteract glutamate toxicity. Our results show that HS at both the tested concentration effectively scav- enged the free radical formation, increased the level of glutathione, augmented antioxidant response elements, improved MMP, and protected HT-22 cells from glutamate-induced degeneration. HS extract has been previously reported to ameliorate serum/glucose deprivation-induced oxidative stress in PC12 cells [23]. Additionally, HS extract also restored the expression of glutamate transporters EAAT-3, and GLT-1 indicating that the extract could facilitate the clearance of excess glutamate in the synaptic cleft.

Oxidative stress is also implicated in disrupting calcium homeostasis in cells, and inhibition of calcium overload was shown to inhibit glutamateinduced toxicity [38]. Alterations in the $\mathrm{Ca}^{2+}$ level activates calpain-1, a member of calcium-activated cytoplasmic cysteine proteases, and play a cru- 

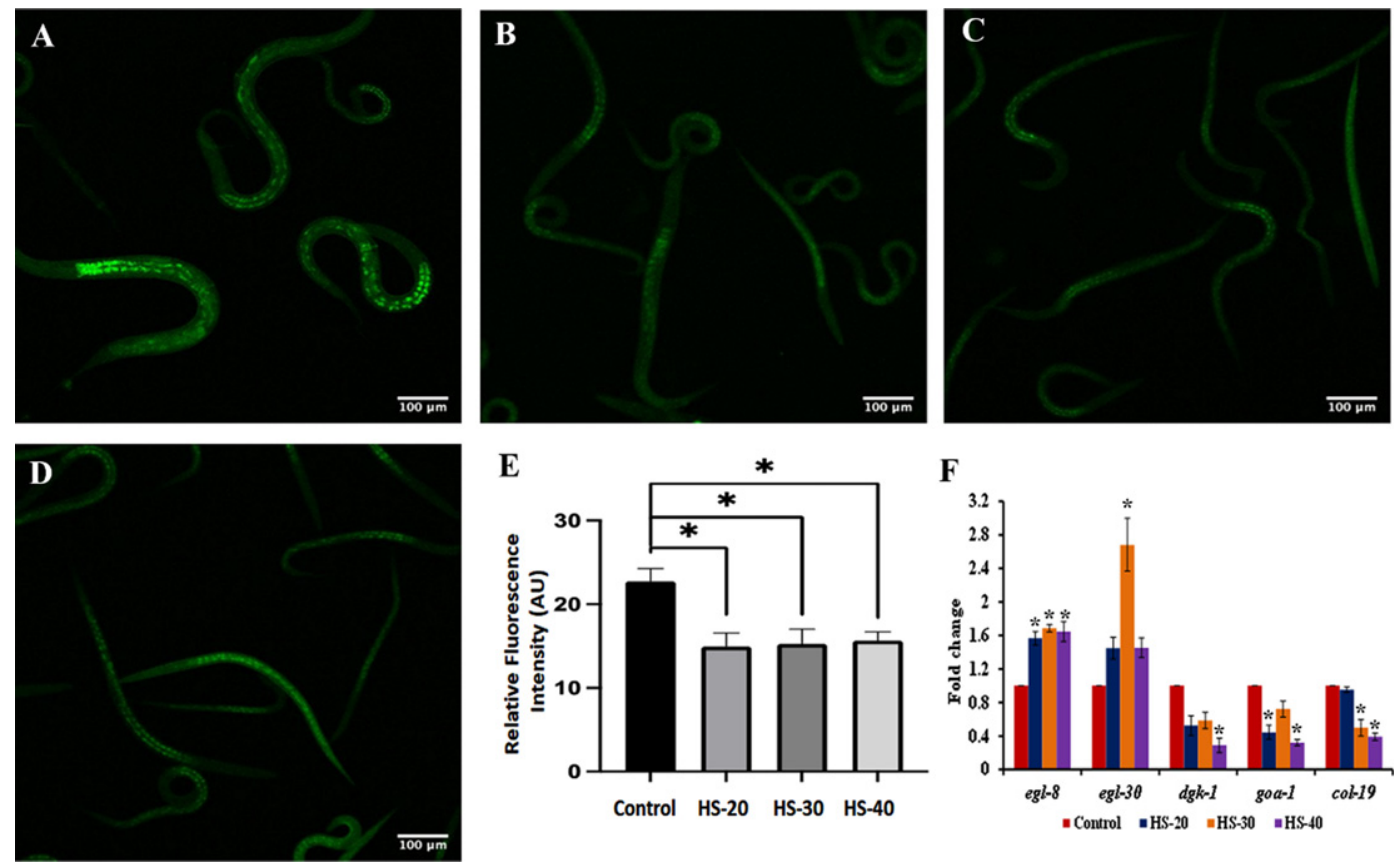

Fig. 12. Representative confocal microscopic images of nematodes showing reduction in lipofuscin accumulation upon treatment with HS (A) Control (B) HS-20 (C) HS-30 (D) HS-40. (E) Quantitative analysis of relative fluorescence of lipofuscin (F) Transcriptional regulation of healthspan related genes (egl-8, egl-30, dgk-1, goa-1, col-19) by HS (* significant level at $p<0.05)$.

cial role in neurodegenerative diseases [39-41]. Calcium deregulation is also associated with ER stress, leading to a stress response mechanism called unfolded protein response (UPR), which initially is aimed at restoring homeostasis condition but eventually induces cell death upon prolonged stress [42]. Recent studies have shown links between UPR and autophagy-induced cell death [43]. ER stress has been reported to activate glycogen synthase kinase-3 $\beta(G S K-3 \beta)$ [44], which further activates the autophagy pathway [45]. Also, Grp-78/Bip acts as a master regulator of UPR, can activate the downstream effectors (IRE-1, PERK, and ATF-6) of the mechanism, which in turn can also activate various autophagy-related genes/proteins (Beclin-1, ATG-5, ATG-7, LC3-II) through MAPK (JNK, p38) pathway [46-48]. Glutamate-induced autophagy activation has been previously reported in HT-22 cells and the inhibition of which by small molecules have been found to be neuroprotective [49-51]. JNK activation induces the tumor suppressor gene p53, which plays a crucial role in mediating glutamate-induced cytotoxicity. Previous studies in HT-22 cells show that in response to oxidative stress p53 is activated resulting in the increased expression of GADD $45 \alpha$ to induce apoptosis [52]. However, pre-treatment with HS extract significantly inhibited autophagic response in a dose-dependent manner by attenuating ER stress and inhibiting MAPK pathway (p-p38 and p-JNK). Further, HS treatment also resulted in the suppression of JNK-mediated apoptosis, which could be corroborated with the earlier studies, in which pharmacological inhibitors of JNK activation were found to increase the survival of cells [52].

Molecular docking, which has become an alternative approach for screening ligands, has been incorporated in the study to support the data observed from in vitro studies (Calpain-1, GSK$3 \beta$ ) except for NMDAR, as undifferentiated HT-22 cells lack the glutamate receptor. The hyperactivation of the glutamate receptor NMDAR occurs majorly in the neurons to mediate glutamate excitotoxicity. Small molecules that bind with N2B subunit of NMDAR and inhibit the activity can help in reducing the excitotoxic condition [53]. The compounds ethyl linoleate, oleamide, 5-methylfurfural, 2-(diethoxymethyl)furan, ethyl palmitate showed higher or relatively similar binding score compared with the reference compound against all the target proteins, indicating the test compounds can act as potent inhibitors against the target biomolecules and the neuroprotective effect of HS extract against glu- 
A

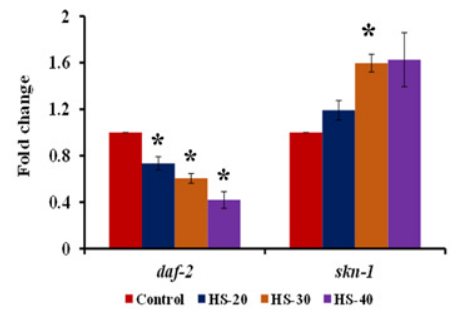

B
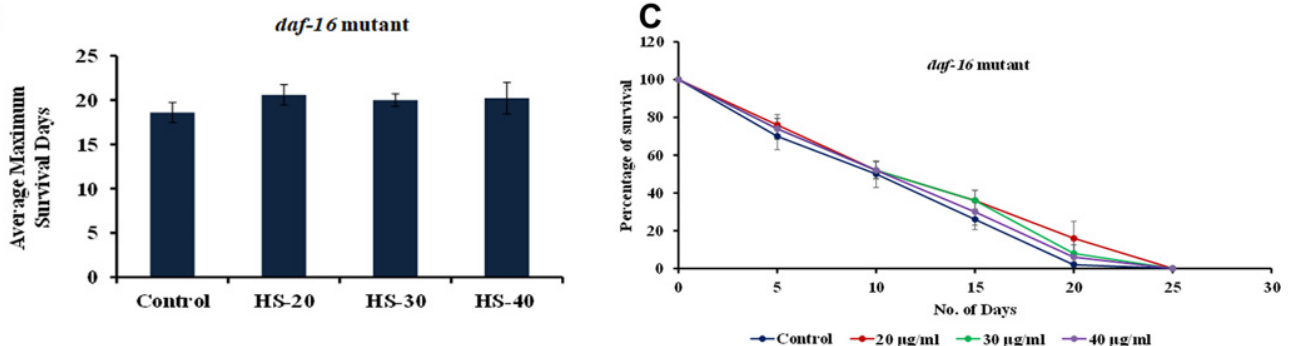

D
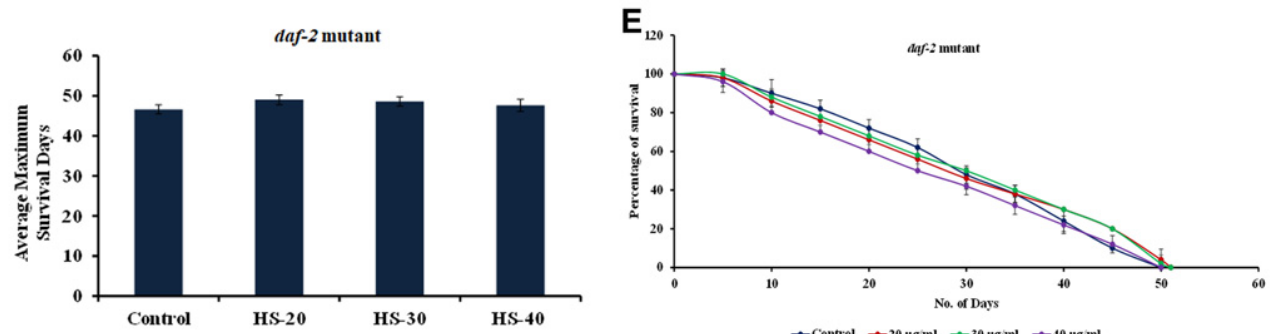

Fig. 13. (A) Transcriptional regulation of antioxidant response gene $s k n-1$ and lifespan extension related gene daf-2 by HS (B) Maximum lifespan of DAF-16 mutants upon treatment with varying concentration $(20-40 \mu \mathrm{g} / \mathrm{ml})$ of HS extract (C) Graphical representation of life span analysis by HS extract $(20-40 \mu \mathrm{g} / \mathrm{ml})$ in DAF-16 mutants (D) Maximum lifespan of DAF-2 mutants upon treatment with varying concentration $(20-40 \mu \mathrm{g} / \mathrm{ml})$ of HS extract (C) Graphical representation of life span analysis by HS extract $(20-40 \mu \mathrm{g} / \mathrm{ml})$ in DAF-2 mutants (* significant level at $p<0.05$ ).

tamate toxicity would be due to the presence of the phytochemicals. In addition, some of the compounds have been reported to exhibit neuro-protective effect against various insults. 2,4-Di-tert-butylphenol has been found to in-crease learning and memory in mice and protect PC12 cells from $A \beta_{1-42}$ insult [54]. Oral administration of oleamide in the kainate-induced epileptic model showed significant neuroprotection against excitotoxicity by inhibiting calpain-1 [55], which could also be corroborated with our findings from gene expression and docking analysis. Further, oleamide can also regulate calcium homeostasis indicating its ability to inhibit ER stress conditions [56]. 5-Hydroxymethylfurfural exhibited neuroprotective property by activating Nrf-2/ARE signaling pathway in cerebral ischemia animal model [57] and improved cognitive impairment in $A \beta_{1-42}$ mouse model by inhibiting $\beta$-secretase activity [58]. Ethyl linoleate showed an anti-inflammatory effect by inducing the expression of HO-1 in RAW264.7 cells [59]. Apart from the compounds identified, previous reports using LC-MS analysis have also reported on the presence of various polyphenols with neuroprotective activities including luteolin, myricetin, kaempferol, quercetin, protocatechuic acid, and hibiscus acid [60, 61].

One of the limitations on the development of drugs against neurodegenerative diseases is their inability to transverse across BBB [62]. Recently, several in silico prediction tools are available, which helps to screen the properties of compounds. The computeraided prediction methods have been reported to be highly efficient due to less time consumption and cost effectiveness [63, 64]. The compounds including oleamide, 5-methyl furfural, and palmitic acid which exhibited highest binding efficiency against NMDAR, Calpain- 1 and $G S K-3 \beta$ were found to be BBB permeant corroborating with the earlier reports indicating the compounds of $\mathrm{HS}$ extract could transverse across BBB and exert their neuroprotective activity by interfering with signaling pathways [65-68]. 
In addition to the neuroprotective effect, the antiaging effect of HS extract was analyzed in the in vivo model system C. elegans. The water extract of HS has been previously reported to extend the lifespan of the nematodes [69]. In accordance to the study, ethanol extract of HS also showed lifespan extension property in a dose-dependent manner. It has been reported that during aging process, there is an accumulation of autofluorescent age pigment lipofuscin throughout the body parts of the nematodes, which results in the generation of ROS leading to deterioration of healthspan and apoptosis [70]. HS extract significantly reduced the accumulation of lipofuscin indicating the slowing down of aging process. Further, the improvement in the overall healthspan of the nematodes was assessed by the transcriptional regulation of candidate genes involved in Diacyl glycerol (DAG) pathway. The genes $d g k-1$, goa- 1 negatively regulates acetylcholine release thereby causing defects in locomotion and egg laying while egl-8, egl-30 plays the opposite role [71-73]. HS significantly downregulated $d g k-1$, goa$l$ and upregulated egl-8, egl-30 indicating its role in increasing healthspan in C. elegans. Further, the expression of col-19 which is an indicator of aging is also downregulated indicating that the extract can also exert anti-aging effect $[74,75]$.

Oxidative stress is one of the key mechanisms involved in aging and is modulated by SKN-1/Nrf-2 transcription factor in C. elegans. Pioneering studies reports that $\mathrm{SKN}-1$ plays a major role in alleviating oxidative stress and activates the downstream activators of the pathway to extend lifespan [76, 77]. HS extract induced the expression of $s k n-1$ indicating the antioxidant potential of the extract. In C. elegans the reduction in activity of DAF-2 (mammalian ortholog of insulin like growth factor receptor 1) contributes to lifespan extension, stress resistance by mediating the activation of DAF-16, the ortholog of human FOXO$1[78,79]$. Although an increase in lifespan of DAF-2 mutants were observed, HS treatment did not exhibit any significant changes when compared to the control. Likewise, extract treatment did not show any significant increase in lifespan in DAF-16 mutants, indicating the anti-aging effect of HS is mediated through DAF-16 mechanism. Our results show that the ethanol extract of $H$. sabdariffa exerts neuroprotective and anti-aging effect by modulating key mechanisms involved in the pathogenesis.

Based on the observed results, the present study implies the pharmacological importance of HS and further emphasize on the need for the evaluation regarding the safety and toxicity in higher model system as herbal extracts exhibit dose-dependent toxicity and lethality in experimental animals [80-82]. Previous studies have reported on the safety profile of ethanol extract of HS. Sub-chronic administration of HS $(50,100,200 \mathrm{mg} / \mathrm{kg}$ bw) for 35 days did not exhibit any lethality to the experimental rats indicating the safety [83]. However chronic administration (90 days) of $2000 \mathrm{mg} / \mathrm{kg}$ bw of HS has been reported to cause adverse effects indicating dose-dependent toxicity [84]. Reports indicate that administration of $200 \mathrm{mg} / \mathrm{kg}$ bw of HS rich in anthocyanin to Swiss albino mice for 21 days reverted streptozotocininduced Alzheimer's condition without any lethality indicating the need for dose optimization [21]. Hence studies regarding the optimization of the dosage level and safety with respect to the long-term administration must be done in the future studies in higher experimental models.

\section{Conclusions}

To summarize, ethanol extract of the calyces of HS exhibited neuroprotective effect against glutamateinduced toxicity by impeding the oxidative stress, inducing the expression of glutamate transporters, augmenting the antioxidant status, inhibiting ERstress mediated autophagy by inhibiting MAPK pathway (Fig. S3). Further, it also extends the lifespan of $C$. elegans through DAF-16 dependent mechanism. Our results suggest that $H$. sabdariffa calyces and its active constituents can be considered as promising therapeutic agent against age-related neurodegenerative diseases.

\section{Acknowledgments}

DSM wishes to thank the Second Century Fund (C2F) for Postdoctoral Fellowship, Chulalongkorn University, Thailand, for the support. MIP and JMB wishes to thank the Ratchadaphiseksomphot Endowment Fund for Postdoctoral Fellowship, Chulalongkorn University.

\section{Funding}

The present work was supported by the Ratchadaphiseksomphot Endowment Fund, Chulalongkorn University (CU_GR_63_82_37_09), and by Natural Products for Neuroprotection and Anti-ageing Research Unit. 


\section{Conflicts of interest}

The authors declare no conflict of interest.

\section{Supplementary material}

The supplementary material is available in the electronic version of this article: https://dx.doi.org/ 10.3233/NHA-210131.

\section{References}

[1] Suzuki M, Nelson AD, Eickstaedt JB, Wallace K, Wright LS, Svendsen CN. Glutamate enhances proliferation and neurogenesis in human neural progenitor cell cultures derived from the fetal cortex. Eur J Neurosci. 2006;24:645-53.

[2] Prasansuklab A, Brimson JM, Tencomnao T. Potential Thai medicinal plants for neurodegenerative diseases: A review focusing on the anti-glutamate toxicity effect. J Tradit Complement Med. 2020;10:301-8.

[3] Riedel G, Platt B, Micheau J. Glutamate receptor function in learning and memory. Behav Brain Res. 2003;140(1-2):1-47.

[4] Monti B, Contestabile A. Blockade of the NMDA receptor increases developmental apoptotic elimination of granule neurons and activates caspases in the rat cerebellum. Eur $\mathrm{J}$ Neurosci. 2000;12:3117-23.

[5] Foran E, Trotti D. Glutamate transporters and the excitotoxic path to motor neuron degeneration in amyotrophic lateral sclerosis. Antioxid Redox Signal. 2009;11:1587-602.

[6] Fernández-Tomé P. Brera B, Arévalo MA, de Ceballos ML. Beta-amyloid 25-35 inhibits glutamate uptake in cultured neurons and astrocytes: modulation of uptake as a survival mechanism. Neurobiol Dis. 2004;15:580-9.

[7] Murphy TH, Miyamoto M, Sastre A, Schnaar RL, Coyle JT. Glutamate toxicity in a neuronal cell line involves inhibition of cystine transport leading to oxidative stress. Neuron. 1989;2(6):1547-58.

[8] Miyamoto M, Murphy TH, Schnaar RL, Coyle JT. Antioxidants protect against glutamate-induced cytotoxicity in a neuronal cell line. J Pharmacol Exp Ther. 1989; 250(3):113240.

[9] Newman DJ, Cragg GM. Natural Products as Sources of New Drugs from 1981 to 2014. J Nat Prod. 2016;79:629-61.

[10] Tonsomboon A, Prasanth MI, Plaingam W, Tencomnao T. Kaempferia parviflora Rhizome Extract Inhibits GlutamateInduced Toxicity in HT-22 Mouse Hippocampal Neuronal Cells and Extends Longevity in Caenorhabditis elegans. Biology. 2021;10:264.

[11] Brimson JM, Prasanth MI, Ciro I, Sukprasansap M, Tencomnao T. Cleistocalyx nervosum var. paniala seed extracts exhibit sigma-1 antagonist sensitive neuroprotective effects in PC12 cells and protect C. elegans from stress via the SKN-1/NRF-2 pathway. Ntrition and Healthy aging, Preprint 2021;1-16.

[12] Prasanth MI, Brimson JM, Chuchawankul S, Sukprasansap M, Tencomnao T. Antiaging, Stress Resistance, and Neuroprotective Efficacies of Cleistocalyx nervosum var. paniala
Fruit Extracts Using Caenorhabditis elegans Model. Oxid Med Cell Longev. 2019;2019:7024785.

[13] Brimson JM, Prasanth MI, Plaingam W, Tencomnao T. Bacopa monnieri (L.) wettst. Extract protects against glutamate toxicity and increases the longevity of Caenorhabditis elegans. J Tradit Complement Med. 2019;10:460-70.

[14] Pattarachotanant N, Tencomnao T. Citrus hystrix Extracts Protect Human Neuronal Cells against High GlucoseInduced Senescence. Pharmaceuticals (Basel). 2020;13:283.

[15] Markaki M, Tavernarakis N. Caenorhabditis elegans as a model system for human diseases. Curr Opin Biotechnol. 2020;63:118-25.

[16] Alexander AG, Marfil V, Li C. Use of Caenorhabditis elegans as a model to study Alzheimer's disease and other neurodegenerative diseases. Front Genet. 2014;5:279.

[17] Kenyon P, Malinek V. Screening drugs for effects on sexual differentiation. Neurobehav Toxicol Teratol. 1984;6(1):1-2.

[18] Da-Costa-Rocha I, Bonnlaender B, Sievers H, Pischel I, Heinrich M. Hibiscus sabdariffa L. - a phytochemical and pharmacological review. Food Chem. 2014;165:424-43.

[19] Lin HH, Chen JH, Kuo WH, Wang CJ. Chemopreventive properties of Hibiscus sabdariffa L. on human gastric carcinoma cells through apoptosis induction and JNK/p38 MAPK signaling activation. Chem Biol Interact. 2007;165:59-75.

[20] Lans CA. Ethnomedicines used in Trinidad and Tobago for urinary problems and diabetes mellitus. J Ethnobiol Ethnomed. 2006;2:45.

[21] El-Shiekh, RA, Ashour RM, Abd El-Haleim EA, Ahmed KA, Abdel-Sattar E. Hibiscus sabdariffa L.: A potent natural neuroprotective agent for the prevention of streptozotocininduced Alzheimer's disease in mice. Biomed Pharmacother. 2020;128:110303.

[22] Seung TW, Park SK, Kang JY, Kim JM, Park SH, Kwon BS, Lee CJ, Kang JE, Kim DO, Lee U, Heo HJ. Ethyl acetate fraction from Hibiscus sabdariffa L. attenuates diabetesassociated cognitive impairment in mice. Food Res Int. 2018;105:589-98.

[23] Bakhtiari E, Hosseini A, Mousavi SH. Protective effect of Hibiscus sabdariffa against serum/glucose deprivationinduced PC12 cells injury. Avicenna J Phytomed. 2015;5:231-7.

[24] Blois MS. Antioxidant determinations by the use of a stable free radical. Nature. 1958;181:1199-200.

[25] Malar DS, Prasanth MI, Shafreen RB, Balamurugan K, Devi KP. Grewia tiliaefolia and its active compound vitexin regulate the expression of glutamate transporters and protect Neuro-2a cells from glutamate toxicity. Life Sci. 2018;203:233-41.

[26] Kang YC, Son M, Kang S, Im S, Piao Y, Lim KS, Song MY, Park KS, Kim YH, Pak YK. Cell-penetrating artificial mitochondria-targeting peptide-conjugated metallothionein $1 \mathrm{~A}$ alleviates mitochondrial damage in Parkinson's disease models. Exp Mol Med. 2018;50:1-13.

[27] Sedlak J, Lindsay RH. Estimation of total, protein-bound and nonprotein sulfhydryl groups in tissue with Ellman's reagent. Anal Biochem. 1968;25:192-205.

[28] Malar DS, Suryanarayanan V, Prasanth MI, Singh SK, Balamurugan K, Devi KP. Vitexin inhibits A $\beta 25-35$ induced toxicity in Neuro-2a cells by augmenting Nrf-2/HO-1 dependent antioxidant pathway and regulating lipid homeostasis by the activation of LXR- $\alpha$. Toxicol In Vitro. 2018;50: 160-71. 
[29] Santos KB, Guedes IA, Karl ALM, Dardenne LE. Highly Flexible Ligand Docking: Benchmarking of the DockThor Program on the LEADS-PEP Protein-Peptide Data Set. J Chem Inf Model. 2020;60:667-83.

[30] Daina A, Michielin O, Zoete V. SwissADME: A free web tool to evaluate pharmacokinetics, drug-likeness and medicinal chemistry friendliness of small molecules. Scientific Reports. 2017;7:42717.

[31] Uttara B, Singh AV, Zamboni P, Mahajan RT. Oxidative stress and neurodegenerative diseases: a review of upstream and downstream antioxidant therapeutic options. Curr Neuropharmacol. 2009;7:65-74.

[32] Yildiz-Unal A, Korulu S, Karabay A. Neuroprotective strategies against calpain-mediated neurodegeneration. Neuropsychiatr Dis Treat. 2015;11:297-310.

[33] Albrecht P, Lewerenz J, Dittmer S, Noack R, Maher P, Methner A. Mechanisms of oxidative glutamate toxicity: the glutamate/cystine antiporter system $\mathrm{xc}$ - as a neuroprotective drug target. CNS Neurol Disord Drug Targets. 2010;3:373-82.

[34] Aoyama K, Suh SW, Hamby AM, Liu J, Chan WY, Chen Y, Swanson RA. Neuronal glutathione deficiency and agedependent neurodegeneration in the EAAC1 deficient mouse. Nat Neurosci. 2006;9:119-26.

[35] Jacob CP, Koutsilieri E, Bartl J, Neuen-Jacob E, Arzberger T, Zander N, Ravid R, Roggendorf W, Riederer P, Grünblatt E. Alterations in expression of glutamatergic transporters and receptors in sporadic Alzheimer's disease. J. Alzheimers Dis. 2007;11:97-116.

[36] Mookherjee P, Green PS, Watson GS, Marques MA, Tanaka K, Meeker KD, Meabon JS, Li N, Zhu P, Olson VG, Cook DG. GLT-1 Loss Accelerates Cognitive Deficit Onset in an Alzheimer's Disease Animal Model. J. Alzheimers Dis. 2011;26:447-55.

[37] Akhter F, Chen D, Yan SF, Yan SS. Mitochondrial Perturbation in Alzheimer's Disease and Diabetes. Prog Mol Biol Transl Sci. 2017;146:341-61.

[38] Ha JS, Park SS. Glutamate-induced oxidative stress, but not cell death, is largely depenent upon extracellular calcium in mouse neuronal HT22 cells. Neurosci Lett. 2006;393: $165-9$.

[39] Lee MS, Kwo, YT, Li M, Peng J, Friedlander RM, Tsai LH. Neurotoxicity induces cleavage of p35 to p25 by calpain. Nature. 2000;405:360-4.

[40] Xu W, Wong TP, Chery N, Gaertner T, Wang YT, Baudry M. Calpain-mediated mGluR1alpha truncation: a key step in excitotoxicity. Neuron. 2007;53:399-412.

[41] Vosler PS, Gao Y, Brennan CS, Yanagiya A, Gan Y, Cao G, Zhang F, Morley SJ, Sonenberg N, Bennett MV, Chen J. Ischemia-induced calpain activation causes eukaryotic (translation) initiation factor 4G1 (eIF4GI) degradation, protein synthesis inhibition, and neuronal death. Proc Natl Acad Sci U S A. 2011;108:18102-7.

[42] Xu C, Bailly-Maitre B, Reed JC. Endoplasmic reticulum stress: cell life and death decisions. J Clin Invest. 2005; 115:2656-64.

[43] Zheng W, Xie W, Yin D, Luo R, Liu M, Guo F. ATG5 and ATG7 induced autophagy interplays with UPR via PERK signaling. Cell Commun Signal. 2019;17:42.

[44] Resende R, Ferreiro E, Pereira C, Oliveira CR. ER stress is involved in Abeta-induced GSK-3beta activation and tau phosphorylation. J Neurosci Res. 2008;86:2091-9.
[45] Nie T, Yang S, Ma H, Zhang L, Lu F, Tao K, Wang R, Yang R, Huang L, Mao Z, Yang Q. Regulation of ER stressinduced autophagy by GSK3 $\beta$-TIP60-ULK1 pathway. Cell Death Dis. 2016;7:e2563.

[46] Deegan S, Saveljeva S, Gorman AM, Samali A. Stressinduced self-cannibalism: on the regulation of autophagy by endoplasmic reticulum stress. Cell Mol Life Sci. 2013;70:2425-41.

[47] B'chir W, Maurin AC, Carraro V, Averous J, Jousse C, Muranishi Y, Parry L, Stepien G, Fafournoux P, Bruhat A. The eIF2 $\alpha /$ ATF4 pathway is essential for stressinduced autophagy gene expression. Nucleic Acids Res. 2013;41:7683-99.

[48] Haberzettl P, Hill BG. Oxidized lipids activate autophagy in a JNK-dependent manner by stimulating the endoplasmic reticulum stress response. Redox Biol. 2013;1:56-64.

[49] Kim H, Choi J, Ryu J, Park SG, Cho S, Park BC, Lee DH. Activation of autophagy during glutamate-induced HT22 cell death. Biochem Biophys Res Commun. 2009;388:339-44.

[50] Kumari S, Mehta SL, Li PA. Glutamate induces mitochondrial dynamic imbalance and autophagy activation: preventive effects of selenium. PLoS One. 2012;7:e39382.

[51] Ma YM, Ibeanu G, Wang LY, Zhang JZ, Chang Y, Dong JD, Li PA, Jing L. Selenium suppresses glutamate-induced cell death and prevents mitochondrial morphological dynamic alterations in hippocampal HT22 neuronal cells. BMC Neurosci. 2017;18:15.

[52] Choi HJ, Kang KS, Fukui M, Zhu BT. Critical role of the JNK-p53-GADD45 $\alpha$ apoptotic cascade in mediating oxidative cytotoxicity in hippocampal neurons. Br J Pharmacol. 2011;162:175-92.

[53] Gawaskar S, Temme L, Schreiber JA, Schepmann D, Bonifazi A, Robaa D, Sippl W, Strutz-Seebohm N, Seebohm G, Wünsch B. Design, Synthesis, Pharmacological Evaluation and Docking Studies of GluN2B-Selective NMDA Receptor Antagonists with a Benzo[7]annulen-7-amine Scaffold. Chem Med Chem. 2017;12:1212-22.

[54] Choi SJ, Kim JK, Kim HK, Harris K, Kim CJ, Park GG, Park CS, Shin DH. 2,4-Di-tert-butylphenol from sweet potato protects against oxidative stress in PC12 cells and in mice. J Med Food. 2013;16:977-83.

[55] Nam HY, Na EJ, Lee E, Kwon Y, Kim HJ. Antiepileptic and Neuroprotective Effects of Oleamide in Rat Striatum on Kainate-Induced Behavioral Seizure and Excitotoxic Damage via Calpain Inhibition. Front Pharmacol. 2017;8:817.

[56] Yamamoto S, Takehara M, Ushimaru M. Inhibitory action of linoleamide and oleamide toward sarco/endoplasmic reticulum Ca2+-ATPase. Biochim Biophys Acta Gen Subj. 2017;1861:3399-405.

[57] Ya BL, Li HF, Wang HY, Wu F, Xin Q, Cheng HJ, Li WJ, Lin N, Ba ZH, Zhang RJ, Liu Q, Li YN, Bai B, Ge F. 5-HMF attenuates striatum oxidative damage via Nrf2/ARE signaling pathway following transient global cerebral ischemia. Cell Stress Chaperones. 2017;22:55-65.

[58] Liu A, Zhao X, Li H, Liu Z, Liu B, Mao X, Guo L, Bi K, Jia Y. 5-Hydroxymethylfurfural, an antioxidant agent from Alpinia oxyphylla Miq. improves cognitive impairment in A $\beta$ 1-42 mouse model of Alzheimer's disease. Int Immunopharmacol. 2014;23:719-25.

[59] Park SY, Seetharaman R, Ko MJ, Kim DY, Kim TH, Yoon MK, Kwak JH, Lee SJ, Bae YS, Choi YW. Ethyl linoleate from garlic attenuates lipopolysaccharide-induced 
pro-inflammatory cytokine production by inducing heme oxygenase-1 in RAW264.7 cells. Int Immunopharmacol. 2014;19:253-61.

[60] Alara OR, Abdurahman NH, Obanijesu EO, Alara JA, Mudalip SKA. Extract-rich in flavonoids from Hibiscus sabdariffa calyces: Optimizing microwave-assisted extraction method and characterization through LC-Q-TOF-MS analysis. J Food Process Eng. 2020;43:e13339.

[61] Widowati W, Rani AP, Hamzah A, Arumwardana S, Afifah E, Kusuma HSW, Rihibiha DD, Nufus H, Amalia A. Antioxidant and Antiaging Assays of Hibiscus sabdariffa Extract and Its Compounds. Nat Prod Sci. 2017;23(3):192-200.

[62] Adenot M, Lahana R. Blood-brain barrier permeation models: discriminating between potential CNS and non-CNS drugs including P-glycoprotein substrates. J Chem Inf Comput Sci. 2004;44(1):239-48.

[63] Castillo-Garit JA, Casanola-Martin GM, Le-Thi-Thu H, Pham-The H, Barigye SJ. A Simple Method to Predict BloodBrain Barrier Permeability of Drug- Like Compounds Using Classification Trees. Med Chem. 2017;13(7):664-9.

[64] Liu L, Zhang L, Feng H, Li S, Liu M, Zhao J, Liu H. Prediction of the Blood-Brain Barrier (BBB) Permeability of Chemicals Based on Machine-Learning and Ensemble Methods. Chem Res Toxicol. 2021;34(6):1456-67.

[65] Hamilton JA, Brunaldi K. A model for fatty acid transport into the brain. J Mol Neurosci. 2007;33(1):12-7.

[66] Li MM, Wu LY, Zhao T, Wu KW, Xiong L, Zhu LL, Fan M. The protective role of 5-hydroxymethyl-2-furfural (5-HMF) against acute hypobaric hypoxia. Cell Stress Chaperones. 2011;16(5):529-37.

[67] Pan Y, Scanlon MJ, Owada Y, Yamamoto Y, Porter CJ, Nicolazzo JA. Fatty Acid-Binding Protein 5 Facilitates the Blood-Brain Barrier Transport of Docosahexaenoic Acid. Mol Pharm. 2015;12(12):4375-85.

[68] Heo HJ, Park YJ, Suh YM, Choi SJ, Kim MJ, Cho HY, Chang YJ, Hong B, Kim HK, Kim E, Kim CJ, Kim BG, Shin DH. Effects of oleamide on choline acetyltransferase and cognitive activities. Biosci Biotechnol Biochem. 2003;67(6):1284-91.

[69] Koch K, Weldle N, Baier S, Büchter C, Wätjen W. Hibiscus sabdariffa L. extract prolongs lifespan and protects against amyloid- $\beta$ toxicity in Caenorhabditis elegans: involvement of the FoxO and Nrf2 orthologues DAF-16 and SKN-1. Eur J Nutr. 2020;59(1):137-50.

[70] Höhn A, Jung T, Grimm S, Grune T. Lipofuscin-bound iron is a major intracellular source of oxidants: role in senescent cells. Free Radic Biol Med. 2010;48(8):1100-8.

[71] Govorunova EG, Moussaif M, Kullyev A, Nguyen KC, McDonald TV, Hall DH, Sze JY. A homolog of FHM2 is involved in modulation of excitatory neurotransmission by serotonin in C. elegans. PLoS One. 2010;5(4):e10368.

[72] Matsuki M, Kunitomo H, Iino Y. Goalpha regulates olfactory adaptation by antagonizing Gqalpha-DAG signaling in Caenorhabditis elegans. Proc Natl Acad Sci U S A. 2006;103(4):1112-7.
[73] Miller KG, Emerson MD, Rand JB. Goalpha and diacylglycerol kinase negatively regulate the Gqalpha pathway in C. elegans. Neuron. 1999;24(2):323-33.

[74] Thein MC, McCormack G, Winter AD, Johnstone IL, Shoemaker CB, Page AP. Caenorhabditis elegans exoskeleton collagen COL-19: an adult-specific marker for collagen modification and assembly, and the analysis of organismal morphology. Dev Dyn. 2003;226(3):523-39.

[75] Prasanth MI, Santoshram GS, Bhaskar JP, Balamurugan K. Ultraviolet-A triggers photoaging in model nematode Caenorhabditis elegans in a DAF-16 dependent pathway. Age (Dordr). 2016;38(1):27.

[76] Govindan S, Amirthalingam M, Duraisamy K, Govindhan T, Sundararaj N, Palanisamy S. Phytochemicals-induced hormesis protects Caenorhabditis elegans against $\alpha$ synuclein protein aggregation and stress through modulating HSF-1 and SKN-1/Nrf2 signaling pathways. Biomed Pharmacother. 2018;102:812-22.

[77] Zhang H, Davies KJA, Forman HJ. Oxidative stress response and Nrf2 signaling in aging. Free Radic Biol Med. 2015;88(Pt B):314-36.

[78] Zečić A, Braeckman BP. DAF-16/FoxO in Caenorhabditis elegans and Its Role in Metabolic Remodeling. Cells. 2020;9(1):109.

[79] Liu J, Hafting J, Critchley AT, Banskota AH, Prithiviraj B. Components of the cultivated red seaweed Chondrus crispus enhance the immune response of Caenorhabditis elegans to Pseudomonas aeruginosa through the pmk-1, daf-2/daf-16, and skn-1 pathways. Appl Environ Microbiol. 2013;79(23):7343-50.

[80] Asiimve S, Borg-Karlsson AK, Azeem M, Mugisha KM, Namutebi A, Gakunga NJ. Chemical composition and toxicological evaluation of the aqueous leag extracts of Plectranthus amboinicus Lour Spreng. Int J Pharm Sci Invent. 2014;3(2):19-24.

[81] Park MY, Choi HY, Kim JD, Lee HS, Ku SK. 28 Days repeated oral dose toxicity test of aqueous extracts of mahwangyounpae-tang, a polyherbal formula. Food Chem Toxicol. 2010;48(8-9):2477-82.

[82] Seremet OC, Olaru OT, Gutu CM, Nitulescu GM, Ilie M, Negres S, Zbarcea CE, Purdel CN, Spandidos DA, Tsatsakis AM, Coleman MD, Margina DM. Toxicity of plant extracts containing pyrrolizidine alkaloids using alternative invertebrate models. Mol Med Rep. 2018;17(6):7757-63.

[83] Mahfudh N, Ikarini N. In vivo effect of sub-chronic administration of ethanol extract of Rosella (Hibiscus sabdariffa L.) calyx on total blood cholesterol, triglyceride level, and heart histopathologic profile. Int Food Res J. 2018;25(3):1253-57.

[84] Fakeye TO, Pal A, Bawankule DU, Yadav NP, Khanuja SP. Toxic effects of oral administration of extracts of dried calyx of Hibiscus sabdariffa Linn. (Malvaceae) Phytother Res. 2009;23(3):412-6. 